Um estudo do problema de escolha de portfólio ótimo

Guilherme Ulliana Vieira de Albuquerque 
SERVIÇO DE PÓS-GRADUAÇÃO DO ICMC-USP

Data de Depósito:

Assinatura:

\title{
Um estudo do problema de escolha de portfólio ótimo
}

\author{
Guilherme Ulliana Vieira de Albuquerque
}

Orientadora: Profa. Dra. Franklina Maria Bragion de Toledo

Dissertação apresentada ao Instituto de Ciências Matemáticas e de Computação - ICMC-USP, como parte dos requisitos para obtenção do título de Mestre em Ciências - Ciências de Computação e Matemática Computacional.

USP - São Carlos

Março/2009 


\section{AGRADECIMENTOS}

À prof ${ }^{a}$ Franklina pela orientação, pelos conselhos para o trabalho e para a vida, e por sempre me motivar a seguir em frente.

Aos professores que me fizeram parte deste trabalho, ministrando aulas ou ajudando com sugestões, em especial Aquiles Kalatzis, Alysson Costa e Marcos Arenales.

Ao amigo André Bassi pela colaboração.

À CNPq pela credibilidade e apoio financeiro.

Aos meus pais pelo amor, orientação, bons conselhos, credibilidade e apoio financeiro, sempre que fosse necessário.

Aos meus amigos do LOT e aos amigos que comigo dividiram moradia, pela ajuda e paciência.

À minha amada Paula, pelo amor e conforto nas horas difíceis.

À Deus, inefável. 


\section{RESUMO}

O processo de escolha de portfólios é um problema clássico da área financeira. Neste problema, o investidor busca aplicar seu dinheiro em um mercado de ações de forma a obter um bom compromisso entre o retorno esperado e o risco. Em geral, quanto maior o retorno esperado da carteira, maior o risco a ela associado. Neste trabalho foram estudadas modelagens para o problema de escolha de portfólio ótimo e suas aplicações ao mercado brasileiro. Do ponto de vista de modelagem foi proposta a inclusão do risco diversificável e não-diversificável ao modelo linear estudado. O risco diversificável foi incluído através de uma restrição que impõe um número mínimo de ativos na composição do portfólio ótimo, enquanto o risco não-diversificável foi adicionado considerando o beta da carteira. Do ponto de vista de aplicação, foi considerada a atribuição de valores de probabilidade para os retornos históricos dos ativos utilizados na análise do problema, visando incorporar informações do comportamento apresentado pelo mercado nos resultados. Na geração dos resultados, foram desenvolvidos em CPLEX um método ótimo de solução para o problema e um método para geração de uma curva de soluções Pareto ótimas.

Palavras-chave: portfólios ótimos, programação inteiro-mista, curva de Pareto, análise de risco. 


\section{ABSTRACT}

The process of selecting a portfolio is a classical problem in finance, where the investor intends to invest money in the stock market in such way that a reasonable trade-off between expected return and risk is obtained. In general, the higher the expected return of the portfolio is, the higher his risk will be. In this work the single period portfolio optimization problem is studied in terms of modeling and application for the Brazilian stock market. Referring to the model, changes are proposed to include the diversifiable and nondiversifiable risk. The diversifiable risk is included by imposing a minimum number of assets on the portfolio, while the nondiversifiable risk is controlled by restricting the portfolio's beta. On the application's side, a method to estimate the probability of the asset's historical returns is proposed, so more information about the market behavior is considered on the problem. The results were obtained by a optimal method to find the best solution and another one to generate the Pareto-optimal solutions, both developed using CPLEX.

Keywords: single-period portfolio selection problem, mixed-integer programming, Pareto curve, risk analysis. 


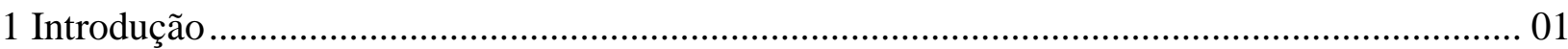

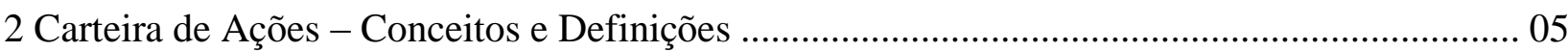

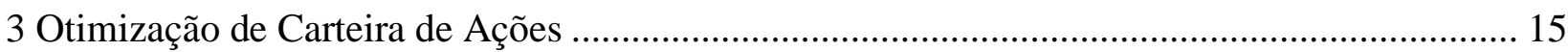

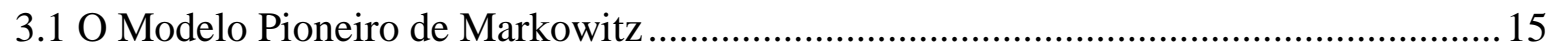

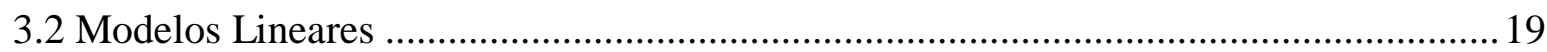

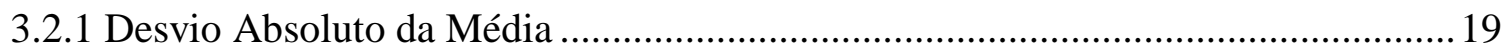

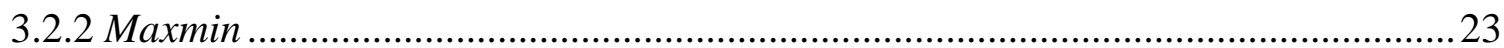

3.2.3 Semi-Desvio Absoluto da Média......................................................................25

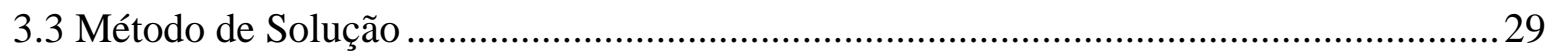

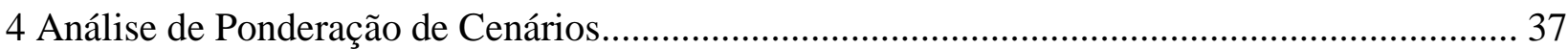

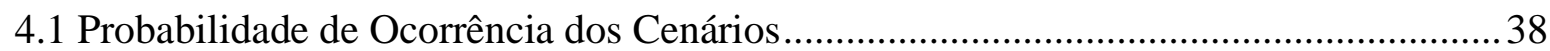

4.2 Dados e Resultados Computacionais...........................................................................4

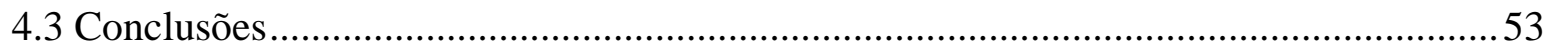

5 Modelo Proposto e Curva de Pareto .........................................................................................55

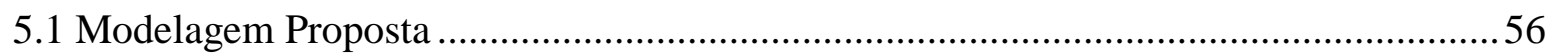


5.3 Testes Computacionais 61

5.4 Análise do Comportamento da Carteira .68

5.5 Conclusões. 70

6 Conclusões e Trabalhos Futuros .71

Referências Bibliográficas .75

Apêndice A .79 


\section{Capítulo 1 - Introdução}

Um dos mais importantes problemas relacionados ao investimento em ações refere-se à composição de uma carteira (ou portfólio) de ações que satisfaça ao máximo o desejo do investidor. A satisfação máxima do investidor está diretamente relacionada ao risco e ao retorno que o portfólio ou a ação oferecem. Na maioria das vezes, procura-se maximizar o retorno da carteira sujeito a certo nível de risco que o investidor aceita assumir, ou então minimizar o risco para um dado nível de retorno mínimo pré-estabelecido. As carteiras que conseguem atingir esses resultados, respeitando as condições impostas, são denominadas carteiras eficientes. A obtenção de tais carteiras não é um processo simples, e para tal, vários autores propõem métodos computacionais.

O problema de escolha de portfólio ótimo foi modelado matematicamente pelo pioneiro Harry Max Markowitz (prêmio Nobel de Ciências Econômicas - 1990) em 1952 e, desde então, diversas outras formulações foram e têm sido estudadas e desenvolvidas com base nos princípios do modelo proposto pelo autor, o qual ficou conhecido como modelo média-variância $(M-V)$. Os objetivos de satisfação do investidor são dados em termos dos retornos observados das ações no passado, e o portfólio ótimo pode ser obtido de duas formas: maximização do retorno esperado ou minimização do risco esperado. O autor utiliza a variância como medida de risco, o que resulta em um modelo de otimização quadrático (Mansini et al., 2003). Como resultado, o problema é muito difícil de ser resolvido computacionalmente, principalmente quando são consideradas suas características reais, como a compra de ações por lotes, ou a imposição de limites mínimos e máximos para os investimentos (Mansini e Speranza, 2005). Além disso, apesar de amplamente aceito por sua relevância teórica, o modelo $M$ - $V$ tem como ponto fraco ser incompatível com os axiomas dos modelos de escolha sob condições de risco (Whitmore e Findlay, 1978). 
Sharpe (1971) e Stone (1973) usam vários esquemas de aproximação para tentar diminuir a dificuldade de resolução do modelo $M-V$, mas estes ainda demandam esforços computacionais elevados (Konno e Yamazaki, 1991). Sharpe (1971) notou que, se a essência do problema de análise de portfólio pudesse ser adequadamente modelada por um modelo de programação linear, as possibilidades de aplicação prática destes modelos seriam consideravelmente ampliadas (Stone, 1973; Young, 1998).

Konno e Yamazaki (1991) propuseram o primeiro modelo de programação linear para o problema de escolha de portfólio ótimo. Este modelo está baseado no desvio absoluto da média como medida de risco. Nesta mesma linha de raciocínio, Young (1998) propôs duas novas formulações equivalentes para o problema, cujo objetivo é maximizar o retorno mínimo da carteira, baseada em dados históricos. Tais formulações são equivalentes ao modelo quadrático $(M-V)$ quando os retornos têm distribuição normal multivariada. Speranza (1996) e Mansini e Speranza (1999) também desenvolveram formulações similares baseadas no semidesvio absoluto da média. Papahristodoulou e Dotzauer (2004) utilizam dois modelos lineares, um baseado no desvio absoluto da média e outro, denominado pelos autores "maxmin", que substitui o uso de uma medida de risco direta pela análise do desempenho passado do grupo de ações candidatas a fazerem parte do portfólio. Alguns trabalhos ainda utilizam o modelo $M$ - $V$, como o proposto por Chang-Chun Lin e Yi-Ting Liu (2007), para o qual é desenvolvido um algoritmo genético, visando a obtenção de uma solução próxima da fronteira eficiente.

Tomando por base as modelagens lineares para o problema, Mansini e Speranza (2005) propuseram um modelo inteiro-misto que descreve o problema com a adição de várias características reais, como compra de lotes de ações e custos fixos de investimento. No 
mesmo trabalho, é também apresentado um método de solução que reduz consideravelmente custos computacionais relacionados à obtenção do portfólio ótimo.

Apesar dos grandes avanços obtidos, principalmente após a formulação de modelos lineares, o problema ainda apresenta inúmeras questões abertas a serem exploradas. Do ponto de vista da modelagem, duas hipóteses são consideradas neste trabalho. A primeira baseia-se na ponderação dos cenários dos quais são extraídos os retornos históricos das ações, ou seja, atribui-se diferentes valores de probabilidade de ocorrência para cada cenário considerado no problema. Grande parte dos modelos utilizados na literatura considera que os cenários são equiprováveis. A incorporação de novas informações quanto aos cenários pode melhorar a qualidade do resultado, em termos de proximidade de retorno esperado e retorno efetivo da carteira. A segunda hipótese a ser explorada neste trabalho, do ponto de vista de modelagem, é o número mínimo de ativos que devem fazer parte da carteira e o comportamento da mesma em relação ao comportamento do mercado. Segundo a teoria econômica, é conhecido que uma carteira com vários ativos tem seu risco diversificável reduzido. No entanto, a partir de 20 ativos o ganho marginal é muito pequeno. Nesse sentido, muitos modelos propostos na literatura buscam a diversificação da carteira impondo um limite máximo de investimento em cada ação, não impondo, no entanto, um número mínimo de ativos para a carteira, nem impondo às ações selecionadas baixa correlação entre si, condição para tornar a diversificação algo benéfico ao risco da carteira. Essa hipótese será trabalhada com a adição de restrições que exigem diversificação da carteira, de forma a diminuir seu risco diversificável, e que restrinjam o valor do risco não-diversificável da carteira, o Beta.

Outra proposta deste trabalho é a solução do problema através curva de Pareto, visando fornecer ao investidor diversas soluções viáveis ao problema, visto que o problema possui dois objetivos, a minimização do risco e a maximização do retorno. Com a geração de 
portfólios ótimos distintos para cada faixa de risco ou retorno esperado, caberia ao investidor a decisão sobre qual a melhor carteira de investimento para o período, de forma que este possa levar em consideração sua experiência, ou demais fatores não abordados nas soluções possíveis.

Do ponto de vista do mercado brasileiro, poucos trabalhos que exploram a modelagem do problema de escolha ótima de portfólio foram apresentados, de modo que a escolha do mercado brasileiro como alvo de estudo para este trabalho representa uma contribuição adicional. Neste quesito, são realizados diversos estudos financeiros, que visam avaliar desde a viabilidade de aplicação das soluções obtidas no mercado brasileiro até a pré-seleção de dados referente aos ativos objetivando melhores resultados.

Este trabalho está dividido em seis capítulos. No capítulo a seguir, é apresentado um estudo mais detalhado do problema, acompanhado de uma revisão da bibliografia. No Capítulo 3 são discutidas algumas modelagens para o problema, e é apresentado um método ótimo de solução. O Capítulo 4 traz a análise de ponderação de cenários para o mercado brasileiro e os resultados obtidos. Ao final do capítulo, são consideradas ainda novas oportunidades para o estudo gerado. O Capítulo 5 apresenta a análise do caráter multiobjetivo do problema através das curvas de Pareto e o estudo do modelo proposto, que aborda a diversificação do portfólio e o risco não-diversificável. O Capítulo 6 apresenta as conclusões do trabalho e sugestões para trabalhos futuros. 


\section{Capítulo 2 - Carteira de Ações - Conceitos e Definições}

As definições dos modelos para o problema de escolha ótima de portfólio variam de acordo com os dados fornecidos e as considerações a respeito do problema. Várias características que aproximam o modelo da realidade podem ser estudadas e aplicadas. Dessa forma, neste capítulo, primeiramente, é descrito o problema e, posteriormente, são apresentadas as modelagens propostas na literatura para representá-lo.

A escolha de uma carteira de investimentos está relacionada diretamente a dois fatores importantes: o risco e o retorno. O problema de escolha ótima de portfólio consiste em encontrar a seleção de ações que melhor atenda aos objetivos de seus investidores. Em condições de certeza, o problema de decisão do investidor pode ser caracterizado por um resultado garantido. No entanto, quando há risco o resultado de qualquer decisão não é conhecido com certeza e os resultados possíveis são comumente representados por uma distribuição de frequiências, que consiste de todos os resultados possíveis associados a suas probabilidades (Elton et al., 2004).

O risco é definido como a possibilidade de perda financeira e está associado à incerteza dos resultados dos ativos. Quando se considera uma carteira de ações, existem dois tipos de risco. O primeiro deles é o risco sistemático, que é atribuído a fatores do mercado que afetam todas as empresas e não podem ser eliminados por meio de diversificação, por isso, também é chamado de risco não-diversificável. O segundo tipo de risco é o não sistemático, ou risco diversificável, que é referente à variabilidade dos retornos associados a cada um dos ativos individualmente (Gitman, 2004). No restante deste trabalho, o termo risco será utilizado para descrever o risco não sistemático, pois é esse tipo de risco em que se baseiam as modelagens propostas na literatura. 
O retorno, por sua vez, representa o ganho ou a perda sofrida por um investimento em certo período. A taxa de retorno de uma dada ação em um período $t$ pode ser obtida utilizando a expressão:

$$
r_{t}=\frac{P_{t}-P_{t-1}}{P_{t-1}}
$$

onde

$$
\begin{aligned}
& P_{t}=\quad \operatorname{preço~(valor)~do~ativo~no~período~} t \\
& P_{t-1}=\quad \text { preço (valor) do ativo no período } t-1 .
\end{aligned}
$$

As definições dos modelos para o problema de escolha ótima de portfólio variam de acordo com os dados fornecidos e as considerações a respeito do problema. Várias características que aproximam o modelo à realidade podem ser estudadas e aplicadas.

Usualmente não se pode listar a distribuição de freqüências referente a um ativo, pois esta teria muitos valores possíveis e seria impraticável obter suas probabilidades de ocorrência em cada caso. No entanto, é possível representar uma distribuição de freqüências utilizando apenas duas medidas: uma para medir o valor esperado do retorno do ativo e outra para medir a dispersão em torno do valor esperado, representando o risco.

Seja $R=\left(R_{1}, R_{2}, \ldots, R_{n}\right)$ o vetor das $n$ variáveis aleatórias que descrevem a taxa de retorno das $n$ ações. As realizações de $R_{j}$, representadas por $r_{j t}$ para cada período $t$ são conhecidas e obtidas através da análise de dados históricos. Tipicamente, escolhem-se retornos mensais ou semanais. Ao se considerar um total de $T$ períodos, a probabilidade $p_{t}=P\left\{\left(R_{1}, R_{2}, \ldots, R_{n}\right)=\left(r_{1 t}, r_{2 t}, \ldots, r_{n t}\right)\right\}$, para $t=1, \ldots, T$ representa a probabilidade de 
ocorrência do período $t$. O termo cenário é utilizado para descrever um conjunto de períodos agrupados pelo seu contexto, por exemplo, os períodos referentes a um dado mês do ano.

Quando se consideram os últimos $T$ períodos, o valor esperado de um dado ativo $j$ é obtido em relação à média dos retornos por período, ponderados por seus valores de probabilidade:

$$
r_{j}=E\left[R_{j}\right]=\sum_{t=1}^{T} p_{t} r_{j t}
$$

Usualmente, no entanto, os valores de probabilidade de cada período não são conhecidos exatamente para o cálculo de $r_{j}$, devendo ser estimados. Dessa forma, a grande maioria dos autores considera os períodos como sendo equiprováveis e o cálculo do valor esperado de cada ativo torna-se o cálculo de uma média aritmética dos valores obtidos dos dados históricos levantados.

O retorno esperado de um portfólio pode ser calculado de maneira semelhante. Seja $R_{x}$ a variável aleatória que representa a taxa de retorno do portfólio $x=\left(x_{1}, x_{2}, \ldots, x_{n}\right)$, onde cada $x_{j}$ representa a proporção do capital investido no ativo $j$, e $r_{x}$ o valor esperado de $R_{x}$. Desconsiderando dados reais do problema, como custo de transação, compra de ações por lotes ou valor de imposto sobre o retorno, o retorno esperado de um portfólio é dado pela média dos retornos esperados de seus ativos, ponderada pela proporção investida em cada ativo, ou seja,

$$
r_{x}=E\left[R_{x}\right]=E\left[\sum_{j=1}^{n} R_{j} x_{j}\right]=\sum_{j=1}^{n} r_{j} x_{j}
$$

De forma semelhante, as medidas de dispersão também são baseadas na ocorrência de retornos passados e representam a distância dos dados em relação a um valor médio. Algumas 
das medidas de dispersão utilizadas neste trabalho são o desvio padrão, a variância, o desvio absoluto da média e o semi-desvio absoluto da média.

Muitos resultados da teoria econômica e inclusive a modelagem pioneira do problema, proposta por Markowitz (1952), derivam do uso da variância como medida de risco. O cálculo da variância para um dado ativo $j$ é obtido de maneira simples por:

$$
\sigma_{j}^{2}=\frac{1}{T-1} \sum_{t=1}^{T}\left(r_{j t}-r_{j}\right)^{2}
$$

O risco de uma combinação de ativos, entretanto, é muito diferente de uma média ponderada dos riscos dos ativos. É fácil ver essa propriedade ao se representar (2.4) em termos de valor esperado.

$$
\sigma_{j}^{2}=E\left[R_{j}-r_{j}\right]^{2}
$$

De forma análoga, a variância do portfólio $x$ é dada por:

$$
\begin{gathered}
\sigma_{x}^{2}=E\left[R_{x}-r_{x}\right]^{2} \\
\sigma_{x}^{2}=E\left[\sum_{j=1}^{n} R_{j} x_{j}-\sum_{j=1}^{n} r_{j} x_{j}\right]^{2} \\
\sigma_{x}^{2}=E\left[\sum_{j=1}^{n}\left(R_{j}-r_{j}\right) x_{j}\right]^{2} \\
\sigma_{x}^{2}=\sum_{j=1}^{n} x_{j}^{2} E\left[R_{j}-r_{j}\right]^{2}+\sum_{j=1}^{n} \sum_{k=1}^{n} x_{j} x_{k} E\left[\left(R_{j}-r_{j}\right)\left(R_{k}-r_{k}\right)\right]
\end{gathered}
$$




$$
\sigma_{x}^{2}=\sum_{j=1}^{n} x_{j}^{2} \sigma_{j}^{2}+\sum_{j=1}^{n} \sum_{k=1}^{n} x_{j} x_{k} \sigma_{j k} .
$$

O termo $\sigma_{j k}$ em (2.10) é a covariância entre os títulos $j$ e $k$. A covariância representa o valor esperado do produto dos desvios padrões de dois ativos, sendo dessa forma semelhante à variância. No entanto, por ser calculada como o produto de dois desvios distintos, pode ser positiva ou negativa. Por conveniência, a covariância pode ser padronizada, dividindo-se a covariância de dois ativos pelo produto dos desvios padrões desses ativos, obtém-se, portanto, uma medida com as mesmas propriedades da covariância, mas com valores dentro do intervalo $[-1,+1]$, que é dada por:

$$
\rho_{j k}=\frac{\sigma_{j k}}{\sigma_{j} \sigma_{k}} .
$$

A medida representada por (2.11) é o coeficiente de correlação entre os ativos $j$ e $k$. A análise da correlação é muito importante ao se fazer a escolha de uma carteira eficiente, pois a escolha de ações com correlações próximas de zero ou negativas entre si pode proporcionar um menor risco ao portfólio. A correlação entre dois ativos mede o comportamento de um em relação ao outro. Quanto mais próximo de +1 for o valor de $\rho_{i j}$, mais próximo é o comportamento dos dois ativos, ao passo que quanto mais próximos de -1 , mais divergente é seu comportamento. A Figura 2.1 ilustra o comportamento de dois ativos em três situações diferentes de correlação. 
(a)

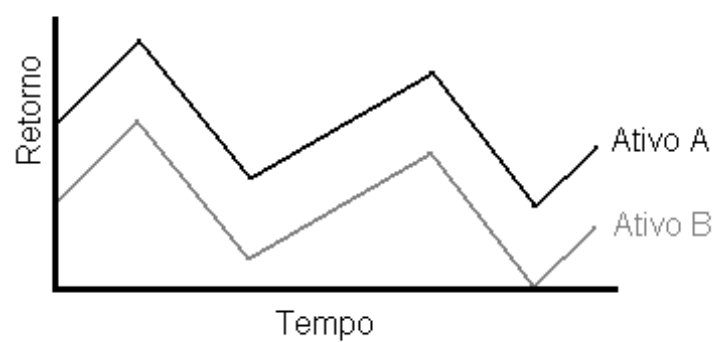

(b)

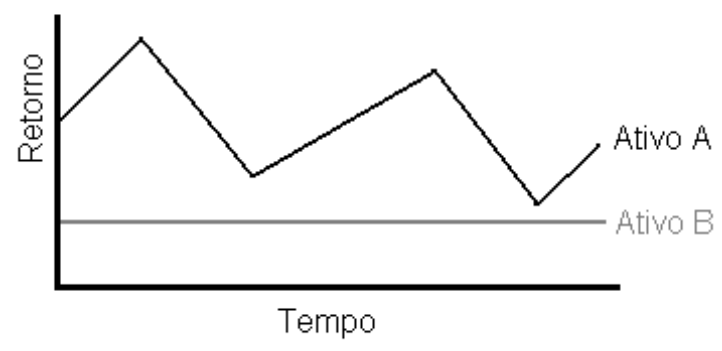

(c)

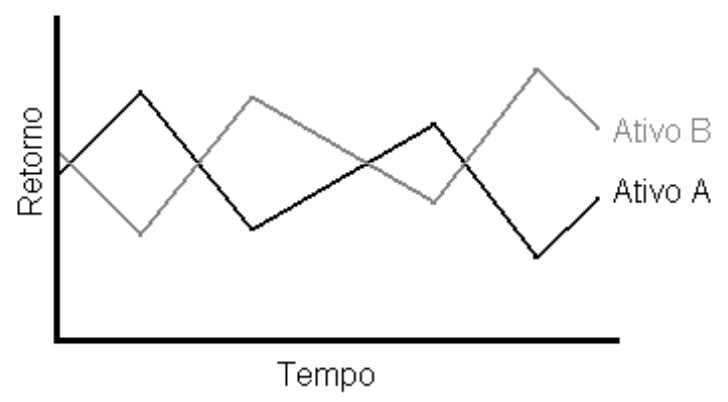

Figura 2.1 - Comportamento de dois ativos, A e B com (a) coeficiente de correlação igual a +1; (b) coeficiente de correlação igual a 0 e (c) coeficiente de correlação igual a -1 .

Alguns resultados importantes ficam evidentes ao se construir um portfólio de dois ativos quaisquer, $a$ e $b$, quando comparados seus possíveis valores de retorno esperado e risco. Se o valor do coeficiente de correlação entre os dois ativos for +1 , substituindo a expressão (2.11) em (2.10), é fácil ver que a variância do portfólio é dada pelo quadrado da média dos desvios padrões dos dois ativos, isso é, o desvio padrão do portfólio é apenas uma combinação linear dos desvios padrões dos dois títulos analisados. Ao se considerar um coeficiente de correlação menor entre os ativos, é possível obter valores de risco para o portfólio que subestimem o valor da combinação linear dos riscos dos ativos individuais.

A Figura 2.2 ilustra a relação entre risco e retorno para portfólios compostos por dois ativos, sob os mesmos valores de coeficiente de correlação. Pode-se observar que o retorno esperado do portfólio, $r_{x}$, encontra-se no mesmo intervalo para todos os valores de correlação. O risco, por outro lado, medido pelo desvio padrão, encontra-se num intervalo que cresce na medida em que a correlação entre os ativos se aproxima de seu valor mínimo. No caso (c), 
onde os ativos possuem correlação negativa perfeita, existe uma proporção de investimento em cada ativo que proporciona risco zero.

(a)

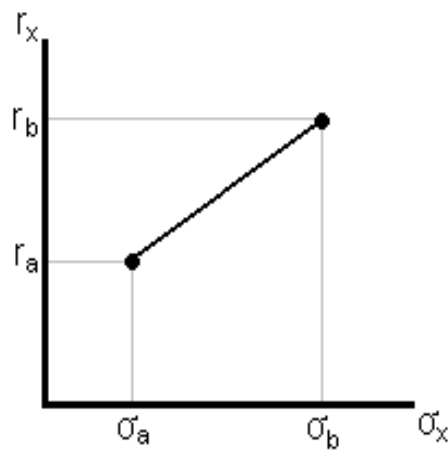

(b)

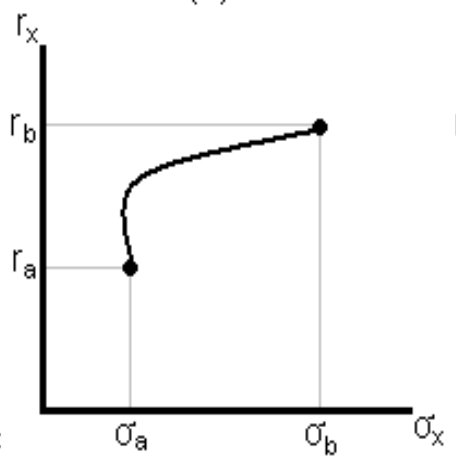

(c)

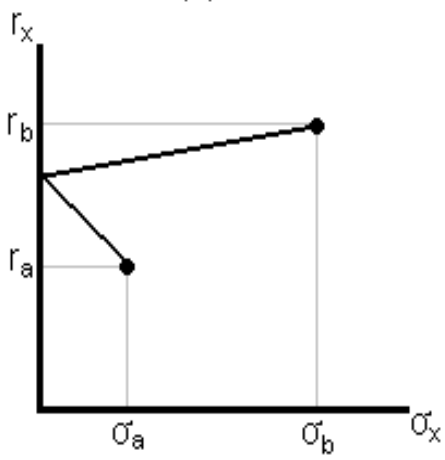

Figura 2.2 - Gráfico de Retorno Esperado x Risco do portfólio, considerando: (a) correlação +1; (b) Correlação 0 e (c) Correlação -1. (Adaptado de Elton et. al, 2004).

Dessa forma, é desejável que uma carteira de ações possua ativos com correlações distantes da correlação positiva perfeita quando o objetivo é a minimização do risco, pois podem ser encontrados portfólios com riscos menores que os riscos dos ativos individuais. Valores de correlação muito próximos de -1 são raros na prática, tornando impraticável a construção de um portfólio livre de risco. Porém, esse resultado é importante ao demonstrar que uma parte do risco diminui com a diversificação, e esse risco pode ser minimizado conforme o portfólio é diversificado (esse risco recebe o nome de risco diversificável), de forma a aproximá-lo de zero (ou seja, pretende-se que o único risco da carteira seja o risco não-diversificável). Porém, segundo estudos teóricos, o ganho marginal da diversificação a respeito do risco decai em torno de 10 ativos, e é muito pequeno para mais de 20 ativos.

O tratamento do risco não-diversificável é feito através do coeficiente beta. O beta é um indicador do grau de variabilidade do retorno de um ativo em resposta a uma variação do retorno do mercado. A observação do comportamento dos preços das ações revela que elas tipicamente reagem ao comportamento do mercado. Esse comportamento sugere que os 
retornos dos títulos são correlacionados em resposta comum a variações do mercado, e uma medida útil dessa correlação poderia ser obtida ao se relacionar o retorno de uma ação ao retorno de um índice de mercado de ações.

Nessa situação, a mensuração empírica do beta pode ser feita mediante a análise de regressão na equação da linha característica:

$$
r_{j}=a_{j}+\beta_{j} r_{m}+e_{j}
$$

Em (2.11), $a_{j}$ representa o valor esperado associado ao componente do retorno do título $j$ que é independente do desempenho do mercado, $e_{j}$ seu termo de erro aleatório, que reflete o risco diversificável do ativo $j, r_{m}$ representa a taxa de retorno do índice de mercado e $\beta_{j}$ é uma constante que mede a variação esperada de $r_{j}$ dada uma variação em $r_{m}$.

O coeficiente beta do mercado é igual a um. Todos os demais são considerados em relação a esse valor, podendo ser positivos ou negativos. Possuir valores de beta maiores do que um, significa que o ativo tende a sofrer variações maiores que as do mercado, seguindo a mesma tendência (de ascensão ou queda). Valores entre 0 e 1 implicam em o ativo apresentar variações menores que as do mercado, seguindo a mesma tendência. Valores de beta negativos, os mais raros, implicam em comportamentos contrários ao do mercado.

O beta de uma carteira pode ser facilmente estimado como a combinação linear dos betas dos ativos que compõem a carteira, segundo a proporção do capital investido em cada ativo, como segue:

$$
\beta_{x}=\sum_{j=1}^{n} x_{j} \beta_{j}
$$


O problema de escolha ótima de portfólio baseia-se em dois princípios básicos: 1) um investidor prefere o portfólio com maior retorno esperado entre outros com o mesmo nível de risco; e 2) um investidor prefere o portfólio com menor risco entre outros com o mesmo retorno esperado. A Figura 2.3 ilustra a região onde pode se situar um portfólio composto por vários ativos, em termos de retorno esperado e risco.

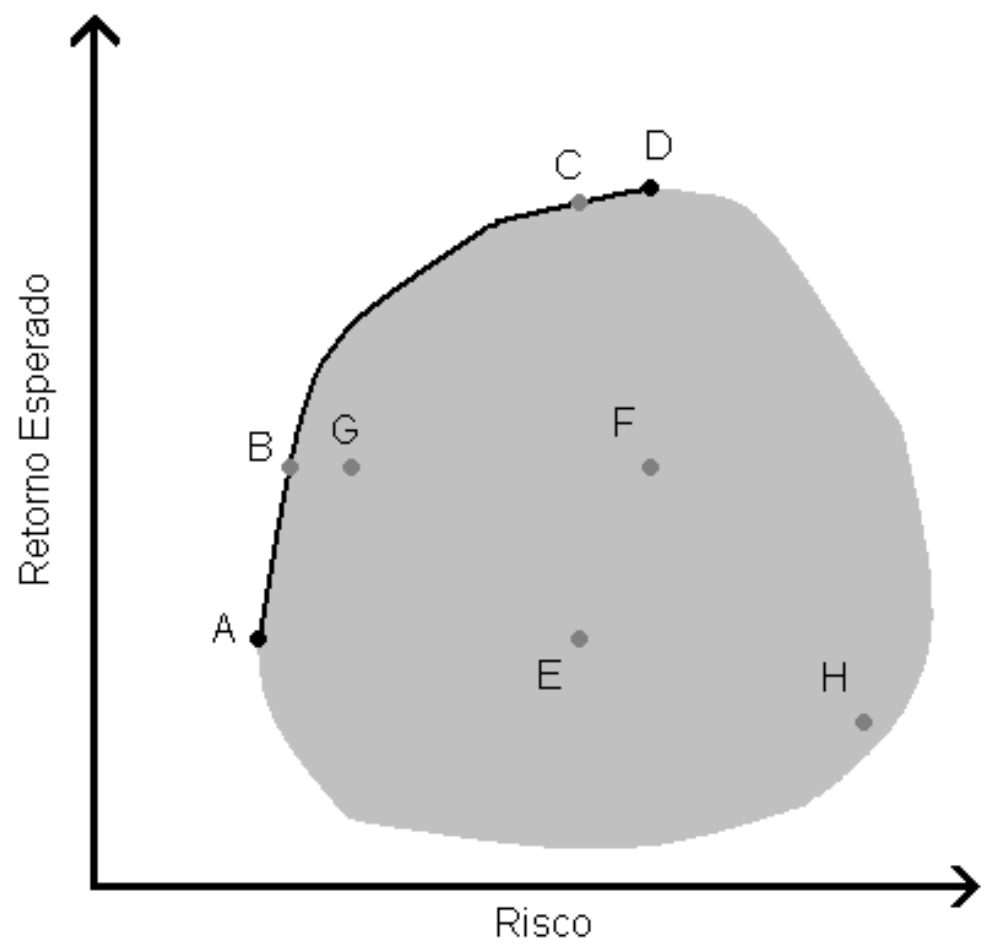

Figura 2.3 - Possibilidades de risco e retorno para uma carteira.

Do ponto de vista de risco e de retorno, tomando como exemplo a Figura 2.3, pode-se afirmar que algumas carteiras são mais eficientes que outras. Na figura, as carteiras $A$ e $E$ estão no mesmo nível de retorno esperado, mas a carteira $E$ possui um risco maior, e, portanto, não é desejada. Da mesma forma, as carteiras $D$ e $F$ estão no mesmo nível de risco, no entanto, a carteira $\mathrm{F}$ possui um retorno esperado menor, o que também a classifica como indesejada. 
Pode-se afirmar que as únicas carteiras que possuem uma relação risco/retorno vantajosa em relação às demais estão compreendidas na linha escura. Também é possível observar que, por exemplo, ao assumir o mesmo nível de risco da carteira ineficiente $E$, não é possível obter um retorno esperado maior que o de $C$. De maneira análoga, assumindo o mesmo nível de retorno esperado de $F$, não é possível obter um risco menor que o de $B$. Ao conjunto de todas as carteiras contidas na linha escura dá-se o nome de fronteira eficiente.

O problema de otimização de portfólio pode então ser resumido a encontrar carteiras próximas à fronteira eficiente, de forma que melhor satisfaçam o perfil do investidor quanto à sua preferência à maior retorno esperado ou menor risco. No capítulo a seguir, são apresentados modelos da literatura para tratar o problema. 


\section{Capítulo 3 - Otimização de Carteira de Ações}

O processo de tomada de decisão para um investimento em carteira de ações requer grande esforço por parte do investidor, pois muitos são os fatores a serem levados em consideração. Enumerar todos os possíveis portfólios para o grande volume de ações existente parece, além de uma tarefa árdua, um esforço desnecessário. Para auxiliar na escolha correta de uma carteira de ações, regras podem ser estabelecidas de forma a medir a eficiência do resultado obtido, não sendo preciso sondar todos os resultados possíveis. A modelagem matemática exerce essa função, pois visa descrever de forma precisa todas as características do problema que devem ser levadas em consideração na escolha do portfólio desejado.

Este capítulo é destinado ao estudo de alguns dos modelos matemáticos propostos para resolver o problema de escolha de portfólio ótimo. Na Seção 3.1, é descrito o modelo pioneiro de Markowitz (1952). Na Seção 3.2, são apresentados modelos lineares propostos para a solução do problema. Na Seção 3.3, é detalhado o método de solução proposto por Mansini e Speranza (2005).

\subsection{O Modelo Pioneiro de Markowitz}

A primeira modelagem do problema de escolha ótima de portfólio foi proposta por $\mathrm{H}$. Markowitz (1952), que ficou conhecido como modelo $M-V$, por utilizar a média e a variância como, respectivamente, medida de retorno e de risco. A decisão de utilizar a variância como medida de risco trás complicações ao problema, tornando-o, como discutido no Capítulo 2, um problema de otimização quadrática de difícil resolução. 
O modelo $M-V$ assume que investidores racionais visam maximizar seu retorno sobre certo nível de risco, ou minimizar o risco acima de certo nível de retorno. Tipicamente, o modelo de minimização de risco sujeito a um dado nível de retorno é o mais utilizado e pode ser descrito como:

$$
\begin{aligned}
& \text { Min } \quad \sigma_{p}^{2}=\sum_{i \in N} \sum_{j \in N} x_{i} x_{j} \sigma_{i j} \\
& \text { s.a: } \quad r_{p}=\sum_{j \in N} x_{j} r_{j} \geq \rho M_{0}, \\
& \sum_{j \in N} x_{j}=M_{0}, \\
& x_{j} \geq 0, \quad j \in N
\end{aligned}
$$

No modelo, $\sigma_{p}^{2}$ é a variância do retorno da carteira e $\sigma_{i j}$ é a covariância do retorno entre as ações $i$ e $j$ (para $i=j, \quad \sigma_{i j}$ representa a variância do ativo $i$ ), sendo $N$ o conjunto dos ativos candidatos a comporem a carteira; $r_{p}$ e $r_{j}$ são, respectivamente, o retorno esperado do portfólio e o retorno esperado da ação $j$, ao passo que $\rho$ representa a taxa de retorno requerida pelo investidor sobre o montante $M_{0}$, que representa o capital disponível para o investimento. Finalmente, as variáveis de decisão $x_{j}$, consideradas contínuas, representam a proporção do capital destinada para investir no ativo $j$. A função objetivo (3.1) visa minimizar a variância do retorno da carteira, enquanto (3.2) exige que o retorno esperado da carteira seja maior ou igual ao retorno exigido pelo investidor, (3.3) assegura que apenas o capital disponível é investido, e (3.4) implica que não é possível realizar vendas a descoberto, ou seja, não é possível obter capital vendendo uma ação que não faz parte da carteira do investidor. 
O modelo pode ser facilmente alterado de forma a maximizar o retorno esperado do portfólio, para tanto, substitui-se a função objetivo (3.1) pela expressão do cálculo de retorno médio descrita em (3.2). Todavia, o risco do portfólio, dado em função da variância, deve ser incluído no portfólio como uma restrição, de forma análoga ao retorno mínimo exigido, ou seja, o investidor deve fornecer como dado para o problema o risco máximo ao qual estaria sujeito. As duas abordagens resultam em problemas de otimização quadrática.

Outro ponto importante é a restrição (3.3), que estabelece a quantia exata a ser investida no portfólio. Se essa restrição fosse modificada de forma a impor $M_{0}$ apenas como o limitante superior de investimento, esta restrição ficaria mais folgada, no entanto, a taxa de retorno requerida pelo investidor seria implicitamente maior do que o exigido na restrição (3.2), uma vez que com um capital menor deve-se obter o mesmo retorno. Dessa forma, a diferença entre as carteiras geradas antes e após essa alteração não seria apenas a proporção de investimento em cada ativo, mas estariam em níveis diferentes de retorno mínimo exigido, não sendo, assim, possível compará-las de uma forma justa. Essa alteração, portanto, só seria possível ao se alterar outras restrições do modelo, o que demandaria um esforço desnecessário para o caso contínuo, mas é necessária ao lidar com modelagens inteiro-mistas do problema, como é discutido na Seção 3.2.

Algumas características reais do problema, tais como a compra de lotes de ações e a existência de custos fixos de transação, quando consideradas no modelo $M-V$, resultam em um problema de otimização quadrática inteiro-misto, muito difícil de resolver de forma exata (Chang-Chun Lin e Yi-Ting Liu, 2008). Muitos autores que utilizam o modelo $M$ - $V$ para tais problemas propõem heurísticas para sua resolução, como é o caso de Chang-Chun Lin e YiTing Liu (2008). Os autores propõem um algoritmo genético para a solução do problema, aplicado a três variações da modelagem de Markowitz. A primeira minimiza a distância entre 
os portfólios obtidos (da solução inteira) e o portfólio alvo (solução contínua, ou relaxada), sob o argumento que a solução inteira para o problema de minimização de risco poderia estar muito distante da solução contínua. Na segunda abordagem, é utilizada programação fuzzy com pesos para os objetivos. A terceira modelagem é semelhante à segunda, porém o investidor atribui pesos segundo sua preferência por retorno e aversão a risco, utilizando ambos os objetivos. O método é aplicado utilizando dados mensais dos fundos mútuos de Taiwan, de 1997 a 2000, gerando soluções próximas das ótimas em tempo computacional razoável. Os portfólios gerados foram considerados aplicáveis na prática por possuírem grande eficiência em termos de média e variância.

Em Baule (2008), o modelo $M$ - $V$ é estendido de forma a considerar custos fixos de transação não lineares (ou seja, o custo fixo é obtido através de uma função na forma $c_{j}=$ $\max \left\{a_{j}, b_{j} x_{j}\right\}$ sempre que $x_{j}>0$ ) e incorporar, na função objetivo, uma medida de utilidade para o investidor, que considera tanto o retorno do portfólio quanto a variância no período. $\mathrm{O}$ autor faz uma comparação entre os modelos com e sem custos fixos, a fim de traçar os impactos causados por eles para os pequenos investidores, que são forçados a investir apenas em um conjunto muito pequeno de ativos. Experimentos foram realizados utilizando os ativos do índice EUROSTOXX 50 e Down Jones industrial average 30, cujos retornos foram estimados a partir, respectivamente, dos preços de fechamento dos índices de mercado XETRA e Down Jones. Os experimentos foram realizados para diferentes faixas de capital disponível para o investimento em cada grupo de ações. A geração dos resultados foi feita através de um método heurístico, e o impacto dos custos fixos foi avaliado em termos de seu custo total e na adição de risco não compensado, uma medida definida pelo autor que representa um risco adicional a carteira que não implica em aumento no retorno esperado. Os resultados mostram que os custos relacionados aos custos fixos e ao risco não compensado na função objetivo decrescem proporcionalmente conforme mais capital está disponível para o 
investimento, mas o ganho marginal é muito pequeno para investimentos superiores a 100.000 euros para os ativos do EUROSTOXX 50, e mesma quantia em dólares para os ativos do Down Jones industrial average 30.

Outros autores, no entanto, para contornar o problema, procuram encontrar medidas de risco que possam ser representadas por expressões lineares. A seção a seguir trata desses modelos.

\subsection{Modelos Lineares}

\subsubsection{Desvio Absoluto da Média}

Uma medida de risco que representou grandes avanços na definição do problema é o desvio absoluto da média. Esta medida foi introduzida por Konno (1988), sendo que a primeira modelagem a utilizá-la foi proposta por Konno e Yamazaki (1991). Partindo das considerações a respeito das variáveis aleatórias descrevendo o retorno dos ativos no modelo $M-V$, os autores concluem que a minimização do desvio absoluto da média corresponde a minimização da variância. A vantagem apresentada pelo novo cálculo de risco é a possibilidade de representação do problema por um modelo linear. Graças a essa simplificação, o modelo ganhou em adaptabilidade, pois mais características reais do problema podem ser adicionadas a ele sem provocar uma queda de desempenho tão brusca quanto apresentaria o modelo $M-V$.

Utilizando a nova medida de risco, o modelo, conhecido como MAD passa a ser descrito como: 


$$
\begin{array}{ll}
\operatorname{Min} \quad w(x)= & E\left[\left|\sum_{j \in N} R_{j} x_{j}-E\left[\sum_{j \in N} R_{j} x_{j}\right]\right|\right] \\
\text { s.a: } & \sum_{j \in N} E\left[R_{j}\right] x_{j} \geq \rho M_{0} \\
& \sum_{j \in N} x_{j}=M_{0}, \\
& 0 \leq x_{j} \leq u_{j},
\end{array} \quad j \in N
$$

onde o valor de $u_{j}$ é um limitante superior para a quantia investida no ativo $j$.

A diferença fundamental entre este modelo e o de Markowitz (1952) é a função objetivo, que reflete a nova medida de risco utilizada. Há também a adição de um limitante superior para os investimentos em um único ativo, visando um maior controle sobre o número mínimo de ações que compõem o portfólio. Alguns procedimentos podem ser aplicados para simplificar o modelo e torná-lo mais prático. Inicialmente, estima-se o retorno esperado das ações como sendo seu retorno médio em um período passado conhecido: $r_{j}=E\left[R_{j}\right]=\sum_{t=1}^{T} r_{j t} / T$, onde $T$ é o horizonte de tempo considerado, e $r_{j t}$ representa o retorno do ativo $j$ no período $t$. Com este valor, pode-se fazer a seguinte aproximação:

$$
w(x)=E\left[\left|\sum_{j \in N} R_{j} x_{j}-E\left[\sum_{j \in N} R_{j} x_{j}\right]\right|\right]=\frac{1}{T} \sum_{j=1}^{T}\left|\sum_{j \in N}\left(r_{j t}-r_{j}\right) x_{j}\right|
$$

Com o objetivo de tornar a expressão (3.9) linear, define-se: $y_{t}=\left|\sum_{j \in N}\left(r_{j t}-r_{j}\right) x_{j}\right|$.

Dessa forma, o modelo pode ser reescrito como: 


$$
\begin{aligned}
& \operatorname{Min} \quad w(x)=\frac{1}{T} \sum_{t=1}^{T} y_{t} \\
& \text { s.a: } \quad y_{t}+\sum_{j \in N}\left(r_{j t}-r_{j}\right) x_{j} \geq 0, \quad t=1, \ldots, T \\
& y_{t}-\sum_{j \in N}\left(r_{j t}-r_{j}\right) x_{j} \geq 0, \quad t=1, \ldots, T \\
& \sum_{j \in N} r_{j} x_{j} \geq \rho M_{0}
\end{aligned}
$$

O objetivo é minimizar o desvio absoluto em relação à média. As restrições (3.11) e (3.12) representam os desvios com valores acima e abaixo da média respectivamente, e podem ser entendidas como uma linearização do módulo de (3.9). As variáveis $y_{t}$ podem ser superiores a esse valor, mas dada a função objetivo de minimizar $y_{t}$, este tenderá a receber os menores valores possíveis. Como implicação direta dessas restrições, sabe-se $y_{t} \geq 0$, $t=1, \ldots, T$.

Em Konno e Yamazaki (1991) também são realizados testes comparativos entre o modelo $M A D$ e o $M$ - $V$, usando como base os dados históricos de 224 ações do mercado de Tókio. Os resultados mostraram-se satisfatórios, visto que ambos fornecem portfólios ótimos com desempenhos similares.

Muitos outros trabalhos utilizam o modelo $M A D$ para a escolha de portfólio ótimo. Em Feinstein e Tappa (1993), são adicionadas ao modelo variáveis de folga, que visam reduzir o número das restrições referentes ao desvio absoluto da média. A função objetivo, nessa modelagem, passa a ser escrita em termos das variáveis de folga. Para testar o novo modelo, foram utilizados 40 testes gerados aleatoriamente, e concluiu-se que as alterações 
representaram uma melhora no desempenho dos métodos de solução para resolver o problema. Posteriormente, Ching-Ter Chang (2005) propõe melhorias na estrutura proposta por Feinstein e Tappa (1993), reduzindo o número de variáveis adicionais e restrições, o que gerou uma melhoria significativa no desempenho dos métodos de resolução do problema para os mesmos conjuntos de testes.

Apesar dos resultados animadores, por muito tempo o uso do desvio absoluto da média como medida de risco foi considerado um simples esquema computacional para a solução do problema de escolha ótima de portfólio. Na conclusão de um trabalho posterior, Konno e Koshizuka (2005) apontam que o $M A D$ não é apenas superior computacionalmente, mas também possui um bom embasamento teórico.

A consideração da média como valor esperado no período pode ser modificada sem perda de generalidade para o modelo, bastando incluir as probabilidades de ocorrências dos períodos no cálculo de valor esperado. Assim, em lugar da média dos retornos anteriores, define-se $r_{j}=E\left[R_{j}\right]=\sum_{t=1}^{T} p_{t} r_{j t}$. Desta forma, a função objetivo torna-se:

$$
w(x)=E\left[\left|\sum_{j \in N} R_{j} x_{j}-E\left[\sum_{j \in N} R_{j} x_{j}\right]\right|\right]=\sum_{j=1}^{T} p_{t}\left|\sum_{j \in N}\left(r_{j t}-r_{j}\right) x_{j}\right|
$$

e, conseqüentemente, a modelagem equivalente é:

$$
\begin{array}{ll}
\text { Min } & w(x)=\sum_{t=1}^{T} p_{t} y_{t} \\
\text { s.a: } & (3.11),(3.12),(3.13),(3.7) \text { e (3.8). }
\end{array}
$$


Esta generalização foi também empregada em outros trabalhos, como em Mansini e Speranza (2005). Apesar disso, nos testes computacionais, períodos são tipicamente considerados equiprováveis na literatura, ou seja, $p_{t}=\frac{1}{T}$.

\subsubsection{MaxMin}

Os modelos apresentados anteriormente tratam de casos em que o objetivo é minimizar uma medida de risco. O modelo maxmin, também conhecido como minmax, difere das demais neste aspecto. Proposto por Young (1998), o modelo concentra-se no objetivo de maximizar o retorno mínimo que o portfólio apresentou no passado analisado. Dessa forma, o risco não é considerado explicitamente, mas o método de solução buscará carteiras que se comportaram bem no horizonte considerado. O modelo é dado por:

$$
\begin{array}{ll}
\operatorname{Max} & \mathrm{Z} \\
\text { s.a: } & \sum_{j=1}^{n} r_{i j} x_{j} \geq Z \quad, t=1, \ldots, T ; \\
& (3.13),(3.7) \mathrm{e}(3.8),
\end{array}
$$

onde a variável $Z$ representa o retorno mínimo para cada período.

A restrição (3.17) no modelo implica que o retorno das ações selecionadas em cada período deve ser superior a um patamar mínimo, que, dada a função objetivo, deve ser o maior possível. Além disso, devido à restrição (3.13), o portfólio com as ações selecionadas deve possuir um valor esperado maior ou igual ao requerido pelo investidor. Dessa forma, 
portfólios são escolhidos respeitando um nível de retorno esperado maior que o requerido pelo investidor e cujo nível de retorno por período é maximizado.

No mesmo trabalho, o modelo proposto foi testado para várias instâncias, que utilizavam como dados de entrada os retornos mensais, desde 1991 até 1995, das ações de oito países. Os resultados mostraram que as carteiras selecionadas se comportam de forma semelhante às geradas pelo modelo $M-V$.

Em Papahristodoulou e Dotzauer (2004), os autores fazem uma comparação da eficiência entre os modelos maxmin, $M A D$ e $M-V$. A motivação para a comparação entre os métodos é o fato dos investidores não aceitarem a dispersão em torno da média de forma simétrica. Os autores argumentam que apenas um pequeno desvio abaixo do valor médio é o suficiente para conflitar com os interesses do investidor, ao passo que apenas para grandes desvios acima da média sua satisfação é ampliada, sugerindo que o tratamento usual do risco poderia não ser adequado para a modelagem do problema. Além disso, os autores também argumentam que se os dados possuírem uma distribuição log-normal, a abordagem maxmin é mais apropriada do que a minimização da variância ou o desvio absoluto da média, que assumem distribuição normal.

Foram realizados testes computacionais que utilizavam os retornos mensais, entre janeiro de 1997 e dezembro de 2000, de 67 ativos da bolsa de valores de Estocolmo. Outras seis observações adicionais (até junho de 2001) são utilizadas para verificar o desempenho dos resultados ao longo do tempo. Os resultados mostraram que o modelo de Markowitz provê os menores riscos, enquanto a formulação maxmin possui os maiores valores de risco e retorno. A minimização do desvio absoluto da média gera resultados muito próximos aos resultados da resolução do modelo $M-V$. Outro resultado importante é que todos os portfólios estimados pela modelagem de Markowitz encontravam-se na fronteira eficiente, assim como 
grande parte dos portfólios estimados pela minimização do desvio médio absoluto. Por não tratar do risco de forma explícita, os resultados do modelo maxmin foram os mais distantes da fronteira eficiente.

\subsubsection{Semi-Desvio Absoluto da Média}

A medida de risco utilizada pela modelagem proposta por Mansini e Speranza em 2005 é derivada diretamente do desvio absoluto da média, mas apenas o semi-desvio abaixo da média é considerado. A proposta é fundamentada nos resultados obtidos em Speranza (1993), onde se mostra que, tomando como função risco a combinação linear dos semidesvios absolutos da média, ou seja, os desvios acima e abaixo do retorno médio do portfólio, um modelo equivalente ao MAD é obtido, desde que os coeficientes da combinação linear sejam não negativos. Com a seleção de coeficientes apropriados, 1 para o semi-desvio abaixo da média e 0 para o semi-desvio acima da média, é possível reduzir substancialmente o número de restrições no modelo e, por conseqüência, o custo computacional para sua resolução. Assim sendo, o termo "semi-desvio absoluto da média" é usado neste documento para se referir à porção dos desvios abaixo da média dos retornos.

Além de definir outra medida para o risco, o modelo utiliza uma função objetivo que incorpora tanto o risco quanto o retorno. O objetivo torna-se maximizar uma medida de segurança, onde o retorno esperado do portfólio é penalizado por seu risco.

Para facilitar a comparação entre os modelos, a modelagem proposta no trabalho de Mansini e Speranza (2005) foi simplificada, de forma a possuir os mesmos parâmetros utilizados nas outras modelagens. O modelo linear é dado a seguir: 


$$
\begin{array}{ll}
\operatorname{Max} & w(x)=\sum_{j=1}^{n} r_{j} x_{j}-\sum_{t=1}^{T} p_{t} y_{t} \\
\text { s.a.: } & (3.11),(3.13),(3.7) \mathrm{e}(3.8) .
\end{array}
$$

A ausência das restrições (3.12) permite que haja desvios acima da média e as restrições (3.11) armazenam os valores dos desvios abaixo da média em cada período. A nova função objetivo (3.18) procura maximizar o retorno esperado, penalizando as carteiras com grande desvio abaixo da média.

Como o retorno e o risco são expressos segundo a mesma unidade, é possível utilizálos em conjunto na função objetivo. Uma alteração possível do método é utilizar ponderações diferentes para risco e retorno, para representar melhor os interesses do investidor. Todavia, neste trabalho, a análise dos diferentes graus de aversão ao risco do investidor foi realizada em termos da curva de Pareto, como é apresentado visto no Capítulo 5.

Mansini e Speranza (2005) também propõem uma série de alterações ao modelo linear para que este passe a apresentar características mais próximas da realidade. A principal característica é a suposição de integralidade nas variáveis de escolha, que se deve ao fato de apenas ser permitido comprar ações por lotes. Também são contabilizados custos fixos de investimento, que representam tanto os custos diretos do investimento em um ativo como, por exemplo, custos de corretagem (brokerage commissions), quanto custos indiretos como, por exemplo, o custo de analisar a ação (Patel e Subrahmanyam, 1982). Esse valor é abatido exclusivamente do retorno no modelo de Mansini e Speranza (2005), pois se assume que esse custo é aplicado somente após o período inicial do investimento. O modelo inteiro-misto é descrito por: 


$$
\begin{array}{lll}
\operatorname{Max} & \sum_{j \in N}\left[(1-g) r_{j} s_{j} x_{j}-c_{j} z_{j}\right]-\sum_{t=1}^{T} p_{t} y_{t} & \\
\text { s.a }: & y_{t} \geq \sum_{j \in N}\left(r_{j}-r_{j t}\right) s_{j} x_{j} & t=1, \ldots, T \\
& \sum_{j \in N}\left[(1-g) r_{j} s_{j} x_{j}-c_{j} z_{j}\right] \geq \mu_{0} \sum_{j \in N} s_{j} x_{j} & \\
& \sum_{j \in N} s_{j} x_{j} \leq C & \\
& x_{j} \leq u_{j} z_{j} & j \in N \\
& y_{t} \geq 0 & t=1, \ldots, T \\
& x_{j} \in Z_{+} & j \in N \\
& z_{j} \in\{0,1\} & j \in N
\end{array}
$$

em que:

$$
\begin{array}{ll}
N & =\text { o conjunto de ativos; } \\
T & =\text { número de períodos; } \\
j & =\text { índice que representa as ações }(j \in N) ; \\
t & =\text { índice que representa os períodos, } t=1, \ldots, T ; \\
g & =\text { imposto pago sobre o retorno obtido (no Brasil é de } 15 \%) ; \\
c_{j} & =\text { custo fixo aplicado somente se houver investimento na ação } j ; \\
r_{j} & =\text { retorno médio da ação } j ; \\
r_{j t} & =\text { retorno da ação } j \text { no período } t ; \\
s_{j} & =\text { preço de cotação da ação } j \text { na data da escolha do portfolio; } \\
u_{j} & =\text { limitante superior para o número de ações } j \text { adquiridas; } \\
\mu_{0} & =\text { taxa mínima de retorno imposta pelo investidor; } \\
C & =\text { capital disponível para investimento; } \\
y_{t} & =\text { semi-desvio da média do portfólio no período t; } \\
x_{j} & =\text { número de ações } j \text { selecionadas; } \\
z_{j} & =\text { variável binária que assume o valor } 1 \text { se a ação } j \text { for selecionada e } \\
& \quad 0 \text { caso contrário; }
\end{array}
$$

A função objetivo (3.19), juntamente com a restrições (3.20), determina a maximização da diferença entre o retorno do portfolio e o risco medido pelo semi-desvio da média. A restrição (3.21) garante que o retorno esperado sob o capital investido deve ser maior ou igual à taxa mínima de retorno especificada pelo investidor, enquanto a restrição 
(3.22) estabelece que o total investido no portfolio não pode exceder o capital disponível para aplicação. Diferentemente do caso contínuo, a quantia investida no portfólio não deve ser igual a um dado patamar. Isso se deve ao fato de não haver, necessariamente, proporcionalidade entre carteiras geradas para diferentes níveis de capital investidos. Mas para o modelo ser condizente com os interesses do investidor quanto ao retorno mínimo, este só é aplicado ao total do capital investido. O conjunto de restrições (3.23) impõe um limite máximo de investimento em cada uma das ações selecionadas $\left(z_{j}=1\right)$, o que complementa a diversificação da carteira. Finalmente, as restrições (3.24) a (3.26) são as restrições de nãonegatividade e de integralidade das variáveis.

As autoras utilizam a modelagem proposta para resolver aproximadamente 100 casos de teste, constituídos a partir dos retornos semanais de ações de quatro mercados internacionais (italiano, francês, inglês e estadunidense), que podem variar de 50 a 1000 ações dependendo do caso de teste, abrangendo períodos entre dois e seis anos. Os resultados foram obtidos de duas formas distintas: a primeira, que utiliza apenas o software CPLEX 7.0 para solução do problema, e a segunda, que incorpora o método CardCut, proposto pelas autoras. A metodologia que apresentou o melhor desempenho foi a que utiliza o método CardCut, cujos resultados ótimos são obtidos com uma redução de $60 \%$ no tempo computacional. Por esse método também ser utilizado na resolução dos problemas deste trabalho, o mesmo é detalhado na Seção 3.3.

Outras medidas de risco também vêm sendo propostas na literatura como em Mansini, Ogryczak e Speranza (2007), onde são analisadas diversas modelagens lineares que utilizam o valor em risco condicional $(C V a R)$. Essa medida é uma extensão do valor em risco $(V a R)$, que mensura a perda máxima que uma carteira pode sofrer em um determinado horizonte de investimento, valendo-se de um nível de confiança. O valor em risco condicional é mais robusto e representa as expectativas de perdas excedentes ao valor em risco. As modelagens 
são testadas utilizando dados semanais de 157 ações do mercado de Milão, entre 1994 e 1999. Para solução do problema foi utilizado o solver CPLEX 6.5. As modelagens que utilizavam o CVaR como medida de risco foram comparadas entre si, e com a modelagem maxmin. Os resultados mostram que essa medida de risco é atrativa para o problema linear, mas apesar de ter recebido importantes resultados também em Guastaroba, Mansini e Speranza (2007), esta medida não será abordada neste trabalho.

\subsection{Método de Solução}

A representação matemática do problema de escolha de portfólio ótimo é uma etapa importante na resolução do problema, pois é a partir desses modelos que métodos de solução podem ser utilizados. Nesse sentido, a qualidade da solução pode não ser unicamente definida como o desempenho da solução, mas sim o custo computacional para obtê-la.

Como foi apresentado anteriormente, o modelo $M-V$ pertence à classe dos problemas quadráticos, e para ser resolvido na otimalidade, devem ser empregados métodos de otimização não-linear. Priorizando o tempo de resposta, heurísticas podem ser utilizadas para se obter soluções próximas da ótima. O modelo $M$ - $V$ não é o foco deste estudo, portanto os métodos de solução não serão apresentados a fundo.

O grupo de problemas lineares pode ser resolvido pelo método Simplex, amplamente difundido devido a sua eficiência e rapidez para se encontrar a solução ótima. Apesar disso, no pior caso, seu desempenho é exponencial em relação à entrada de dados. O Simplex está disponível em pacotes de otimização, como, por exemplo, o $C L P$, software livre da iniciativa COIN-OR, e o CPLEX, software proprietário da ILOG. 
A adição das restrições de integralidade, como proposto no modelo $M S$, torna o problema muito mais difícil de ser resolvido. Uma das abordagens possíveis para a resolução dessa classe de problemas é a enumeração implícita. Nas abordagens por enumeração implícita o problema é dividido em subproblemas, de modo que os conjuntos de soluções factíveis de cada um dos subproblemas sejam menores e dois-a-dois disjuntos. O método mais simples de enumeração implícita é o método branch-and-bound que, através de uma regra de ramificação, gera subproblemas (ou nós) a partir do problema original e de seus subproblemas, formando uma árvore de enumeração. Para evitar a enumeração explícita, o método possui uma regra para eliminar subproblemas que não devem mais ser investigados, baseando-se em limitantes superiores e inferiores. Para problemas de maximização, um limitante superior é obtido por meio de relaxações do problema inteiro e seus subproblemas enquanto um limitante inferior é obtido pelo valor de uma solução factível. Em problemas de minimização, os limitantes são obtidos de maneira oposta.

A geração de limitantes para método Branch-and-Bound pode ser feita a partir da relaxação linear dos subproblemas, que pode ser resolvida pelo método Simplex. Assim sendo, o método Branch-and-Bound resolve um problema linear para cada nó gerado em sua árvore de enumeração.

Algumas adições ao método podem representar ganho em tempo computacional. Um exemplo é o método Branch-and-Cut, que utiliza algumas políticas de corte no espaço de soluções. Mesmo assim, apesar de não realizar uma enumeração explícita das soluções, a árvore de busca pode se tornar muito longa, tornando muito alto o custo computacional para se encontrar a solução ótima. Implementações eficientes do método Branch-and-Cut estão presentes em pacotes de otimização, como o SYMPHONY, software da iniciativa COIN-OR, e o software proprietário da ILOG CPLEX. 
No trabalho de Mansini e Speranza (2005), é proposto um método de solução integrado com o Branch-and-Cut do CPLEX, que se mostrou muito eficiente na resolução do modelo $M S$. O método visa dividir o problema inicial de forma balanceada em dois subproblemas inteiros, onde a solução de um deles é utilizada como limitante para o outro.

Em trabalhos como Mansini e Speranza (1999) e Kellerer et al. (2000), é demonstrado que a relaxação linear do problema, em geral, possui todos os ativos selecionados ao se considerar as restrições de integralidade do problema. Também mostra-se que quando algum ativo do problema inteiro-misto é excluído da solução obtida para sua relaxação linear, este possui um custo relativo muito próximo de zero. Sendo possível estimar quais ativos podem estar presentes no portfólio ótimo, é possível reduzir consideravelmente o espaço da busca do método Branch-and-Cut, levando a um ganho em desempenho computacional.

O método de solução, chamado de CardCut, é constituído de seis passos, que são resumidos à seguir:

Passo 1. Resolva o problema relaxado linear $(R M S)$. Seja $\left\{q_{1}, \ldots, q_{n}\right\}$ os custos reduzidos correspondentes às variáveis $\left\{x_{1}, \ldots, x_{n}\right\}$.

Passo 2. Determine $M=\left\{j \in N:\left|q_{j}\right| \leq\right.$ LIMITE $\}$

Passo 3. Gere os dois subproblemas $M S^{(1)}$ e $M S^{(2)}$ como segue:

- $M S^{(1)}=M S \cup \sum_{j \in N \backslash M} z_{j}=0 ;$

- $M S^{(1)}=M S \cup \sum_{j \in N \backslash M} z_{j} \geq 1$.

Passo 4. Resolva o problema $M S^{(1)}$ utilizando um valor de uma Solução Inicial como limitante inferior; Seja $x^{(1)}$ o vetor da solução ótima e $h_{1}$ seu valor; Se o problema não apresentar soluções factíveis, faça $h_{1}:=-\infty$.

Passo 5. Resolva o problema $M S^{(2)}$ utilizando o valor $h_{l}$ como limitante inferior;

Seja $x^{(2)}$ o vetor da solução ótima e $h_{2}$ seu valor; 
Se o problema não apresentar soluções factíveis, faça $h_{2}:=-\infty$.

Passo 6. Seja $x^{*}$ a melhor solução entre $\left\{x^{(1)}, x^{(2)}\right\}$ e $h^{*}$ seu valor correspondente de solução.

Os Passos 1 a 3 envolvem a divisão dos subproblemas. No método Simplex, o valor do custo reduzido representa o valor associado à adição de uma determinada variável (neste caso um ativo) à solução. As variáveis básicas, ou seja, variáveis que possuem valores entre os limitantes inferior e superior, possuem custos reduzidos iguais a zero. Nesta fase, o objetivo é considerar todas as variáveis básicas e mais aquelas com custo reduzido próximo de zero, ou seja, cuja adição interfere pouco no valor de solução. Espera-se que a solução do problema original contenha apenas proporções de ativos do conjunto $M$.

Entretanto, a escolha de um bom limitante para o valor dos custos reduzidos, que restringe o tamanho de $M$, é muito importante, pois esse valor deve ser grande o suficiente para garantir que $M$ contenha todos os ativos que irão compor o portfólio ótimo do problema original, mas pequeno o suficiente para tornar o primeiro subproblema fácil de se resolver. Em Mansini e Speranza (2005), foi atribuido o valor $10^{-4}$ à variável LIMITE, bons resultados foram obtidos, pois para quase todos os casos de teste obtiveram a solução ótima no primeiro subproblema.

Um fator importante ainda no critério de construção dos subproblemas são os limitantes impostos às variáveis $x$ no modelo $M S$. Representados por $u_{j}$, se os valores desses limitantes forem muito baixos, a seleção de ativos para o conjunto $M$ será prejudicada. Isso se deve ao fato de as variáveis estarem canalizadas, e, nos casos em que assumem seu valor limite, não possuem, necessariamente, valores absolutos de custo reduzido menores que o LIMITE, ainda que essas variáveis estejam presentes na solução relaxada (e, portanto, provavelmente estariam presentes na solução do problema original). Essa limitação é mais 
evidente nos casos em que é de interesse do investidor diversificar seus investimentos ao máximo.

Todavia, esse método não foi alterado no decorrer deste trabalho. A primeira razão é o fato de que os resultados apontaram boa diversificação no portfólio ótimo, mesmo não impondo limitantes superiores baixos para as variáveis. Esses resultados foram alcançados utilizando os mesmos valores de custos fixos de investimento do trabalho de Mansini e Speranza (2005), que eram valores pequenos frente ao montante disponível para a aplicação. A segunda razão foi o fato de que a diversificação da carteira de ações proposta neste trabalho foi representada não pelo limitante superior imposto à compra de cada ativo, mas através de várias restrições que impunham um comportamento referente ao mercado, a compra de um número mínimo de ações, e limitantes tanto inferiores como superiores nas variáveis $x$.

Após a criação do conjunto $M$, com os principais ativos candidatos a compor a carteira ótima, são criados os subproblemas. Estes são formados pelo problema original em conjunto com uma nova restrição. No primeiro subproblema, a restrição incluída não permite o investimento em nenhum ativo que não esteja no conjunto $M$, ao passo que a restrição do segundo subproblema exige que pelo menos um ativo fora do conjunto $M$ seja escolhido.

O Passo 4 visa a obtenção de uma solução para o primeiro subproblema. Utiliza-se uma solução inicial para seu limitante inferior. O uso de uma solução inicial visa aproveitar os resultados do problema relaxado, e reduzir substancialmente o espaço de busca por uma solução ótima. Essa solução inicial pode ser qualquer solução factível já encontrada. A mesma abordagem de impor um limitante inferior é utilizada no segundo subproblema, para o qual é imposto o valor de solução do primeiro subproblema. O resultado do problema é escolhido como o melhor entre os resultados dos subproblemas. 
Para encontrar a solução inicial que limita inferiormente o primeiro subproblema, Mansini e Speranza (2005) definem uma heurística de busca local, (LSH) como segue:

\section{Procedimento Solução Inicial}

Passo 1. Seja $x^{*}$ a solução ótima do problema relaxado;

Calcule $s_{j} x_{j}^{*}$ para todo $j \in M$ na solução;

Calcule a média e o desvio padrão das observações;

Armazene em $l$ o número de ativos que possuem valor de $s_{j} x_{j}{ }^{*}$ maior que a média menos o desvio padrão;

Seja $w$ o número máximo de iterações que a heurística pode executar sem obter melhoria nos resultados.

Passo 2. Enquanto $l \neq|M|$ e $w \neq 0$ faça:

- Adicione ao modelo relaxado a restrição $\sum_{j \in M} z_{j}=l$;

- Resolva o problema relaxado e utilize uma heurística de busca local $(\boldsymbol{L S H})$ para encontrar uma solução inteira. Armazene o valor da solução;

- Remova a restrição adicionada;

- Atualize $l$ e $w$.

\section{Fim Enquanto}

Passo 3. Obtenha melhor valor de solução armazenado e imponha-o como limitante inferior ao primeiro subproblema.

\section{Heurística de busca local ( $\mathrm{LSH})$}

Passo 1. Sejam $x_{j}{ }^{*}, z_{j}{ }^{*}, j \in M$ a solução ótima para o problema $R M S(l, M)$; Seja $x_{j}^{+}:=x_{j}^{*}$ e $x_{j}^{-}:=0, j \in M$

Defina $\bar{M}=\left\{j \in M: z_{j}^{*}>0.5\right\}$. 
Passo 2. Enquanto $\left\lfloor x_{j}^{+}\right\rfloor \neq\left\lfloor x_{j}^{-}\right\rfloor$para algum $j \in \bar{M}$ faça:

- Compute $k:=\frac{\sum_{j \in M} s_{j} x_{j}^{+}}{\sum_{j \in \bar{M}} s_{j}\left[x_{j}^{+}\right]} ;$

- Faça $x_{j}^{-}:=x_{j}^{+}, j \in \bar{M}$;

- Faça $x_{j}^{+}:=\min \left\{u_{j}, k\left\lfloor x_{j}^{*}\right\}, j \in \bar{M}\right.$.

Fim Enquanto

Passo 3. Faça $\bar{x}_{j}:=\left\lfloor x_{j}^{+}\right\rfloor$e $\bar{z}_{j}:=1$ se $j \in \bar{M}$, e $\bar{x}_{j}:=0, \bar{z}_{j}:=0$ caso contrário. Se a solução for factível, calcule o valor correspondente da função objetivo.

O método limita o espaço de busca a um determinado número de ativos pertencentes ao conjunto $M$, representado pela letra $l$. Esse número é atualizado iterativamente de forma a procurar novas soluções, contendo mais ou menos ativos dentro dos limites de $M$. Essa atualização é feita em duas fases: a primeira, chamada de downside search phase, reduz o valor de $l$ em uma unidade a cada iteração visando buscar soluções inteiras com cada vez menos ativos. Essa fase termina quando o valor de $l$ for igual a zero, ou quando a tolerância $w$, que é decrementada a cada iteração onde não haja melhora na solução, for igual a zero.

Ao final da primeira fase de busca, $w$ é atualizado para seu valor inicial, e $l$ é atualizado para uma unidade acima de seu valor inicial. Chamada de upside search phase, essa fase procura encontrar soluções inteiras que contenham mais ativos que a resolução inicial. A partir dos novos valores, $l$ é incrementado a cada iteração, e $w$ é decrementado sempre que a solução inteira não melhora de uma iteração à outra.

Para encontrar as soluções inteiras, a heurística definida recebe como entrada os valores da solução do problema relaxado resolvido. Essa solução é melhorada à partir do valor $k$, que é atualizado de forma a não violar a restrição de capital ao mesmo tempo que melhora a 
solução. $\mathrm{O}$ valor final de $k$ é obtido quando não há diferença entre o piso dos valores de $x$ entre duas iterações.

Durante a realização dos testes, essa condição mostrou-se rígida demais e, em alguns casos, o método não convergiu. Assumindo que houve algum tratamento de convergência no trabalho original, o valor de $k$ também foi controlado, de forma a sair do laço de repetição se a melhoria do valor de solução entre dois cálculos de $k$ for muito pequena.

Em resumo, o método é esquematizado na Figura 3.1.

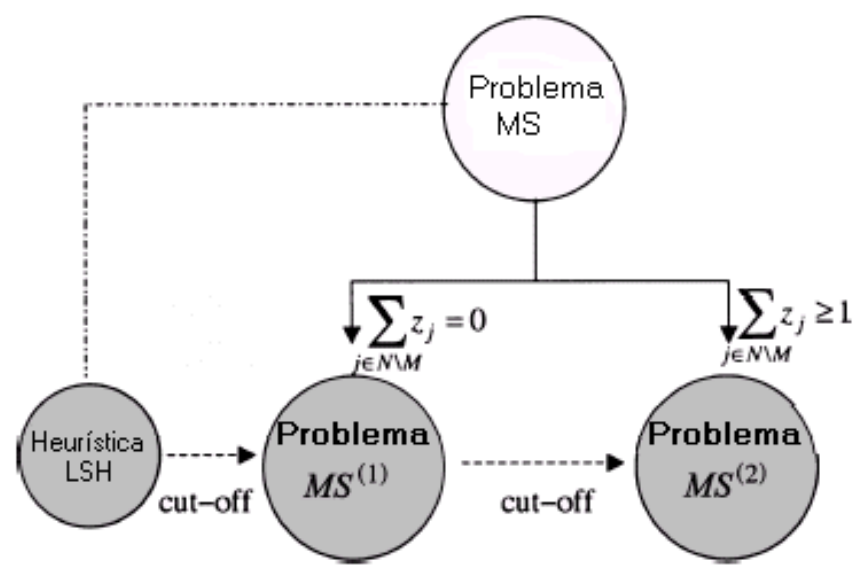

Figura 3.1: Esquema do método de solução (adaptado de Mansini e Speranza, 2005).

Conforme os resultados de Mansini e Speranza (2005), espera-se que, em média, o método de resolução possui um desempenho cerca de $60 \%$ melhor que o método usual de resolução, isso é, utilizando apenas o método branch-and-bound ou o branch-and-cut (que são utilizados nos dois subproblemas, por exemplo). 


\section{Capítulo 4 - Análise de Ponderação de Cenários}

Segundo grande parte dos trabalhos da literatura pouco esforço é direcionado à ponderação dos cenários avaliados, sendo que na geração de resultados considera-se que os cenários sejam equiprováveis. Além disso, poucos trabalhos nacionais abordam o método de escolha ótima de portfólio aqui descrito para o mercado brasileiro, que apresenta diferenças marcantes quanto à eficiência de mercado em relação aos mercados internacionais tipicamente abordados no estudo deste problema.

Mercados de capitais são considerados, de modo informal, eficientes quando todas as informações a respeito de um dado ativo já estão refletidas em seu preço, o que propicia economia de tempo e de recursos que seriam gastos na análise de tais informações. Desta forma, a credibilidade do mercado aumentaria perante o investidor menos especializado em aplicações financeiras, o que poderia aumentar o volume e a quantidade dessas negociações. O mercado brasileiro, por ainda apresentar barreiras a essa adesão, possui menor liquidez e volume negociado por menor número de investidores que os mercados estudados na literatura, apresentando, assim menor eficiência de mercado.

Sendo assim, este capítulo destina-se ao estudo do efeito que a ponderação de cada cenário pode gerar no modelo e em suas soluções, verificando se a ponderação dos cenários pode incorporar mais informações sobre o comportamento do mercado, utilizando o mercado brasileiro como base para o estudo. 


\subsection{Probabilidade de Ocorrência dos Cenários}

Em Guastaroba et al. (2007), é feita uma análise de longo prazo para carteiras ótimas obtidas ao se considerar vários tipos de geração de cenários, sendo que o uso do histórico passado dos ativos mostrou-se eficiente. No entanto, para a geração destes resultados, e de diversos outros resultados na literatura, os retornos históricos dos ativos utilizados na composição da carteira são tipicamente considerados equiprováveis, ou seja, $p_{t}=\frac{1}{T}$, para $t=1, \ldots, T$ representando o número de períodos, pois não é possível conhecer esses valores exatamente. Essa prática é de notável simplicidade e não implica em falhas teóricas para os modelos, sendo ao mesmo tempo, uma solução simples e satisfatória. Ela pode também estar fundamentada na eficiência de mercado, visto que em um mercado eficiente as mudanças nos preços das ações não refletem nova informação e, portanto, as variações ocorridas ao longo do período estudado tendem a ser menos importantes quando o mercado aproxima-se da eficiência. Assim sendo, quando o mercado é considerado eficiente, a abordagem de cenários equiprováveis pode ser justificada.

Entretanto, a eficiência da classificação de cenários históricos como mais ou menos prováveis não é tipicamente abordada na maioria dos trabalhos da literatura. O objetivo é encontrar uma forma justa e que melhor represente o comportamento do mercado e dos ativos candidatos a comporem as carteiras ótimas, de forma que as carteiras escolhidas sejam melhores em termos de retorno efetivo quando comparadas com as carteiras geradas considerando cenários equiprováveis. Este procedimento é fundamentado nos retornos históricos do índice Bovespa (Ibovespa), o mais importante indicador de desempenho médio das cotações do mercado de ações brasileiro, e visa dar um peso maior aos cenários com pouca oscilação no valor do retorno de mercado, sendo assim presumivelmente mais estáveis, 
e um peso menor aos cenários com grande oscilação nos retornos do mercado. Assim sendo, os cenários considerados mais estáveis são preferíveis em relação aos demais. Incorporar essa informação ao modelo pode significar uma maior proximidade ao comportamento do mercado brasileiro, conduzindo a um resultado mais apropriado.

Para essa análise, foram levantados, através do software Economatica, os retornos mensais do mercado brasileiro, desde o início de 1986 até agosto de 2008. Os retornos foram agrupados em seus respectivos meses de ocorrência, cada grupo compondo um cenário. A ponderação de um dado cenário é obtida através da dispersão dos retornos dos períodos em relação à média do cenário.

A fim de verificar a variação do comportamento do Ibovespa em cada período do ano, utilizaram-se três medidas de dispersão: o desvio absoluto da média, o desvio padrão e a variância. Os meses do ano que possuem valores pequenos para essas medidas são considerados mais estáveis que os demais, e, portanto, os cenários correspondentes devem possuir uma maior probabilidade de ocorrência.

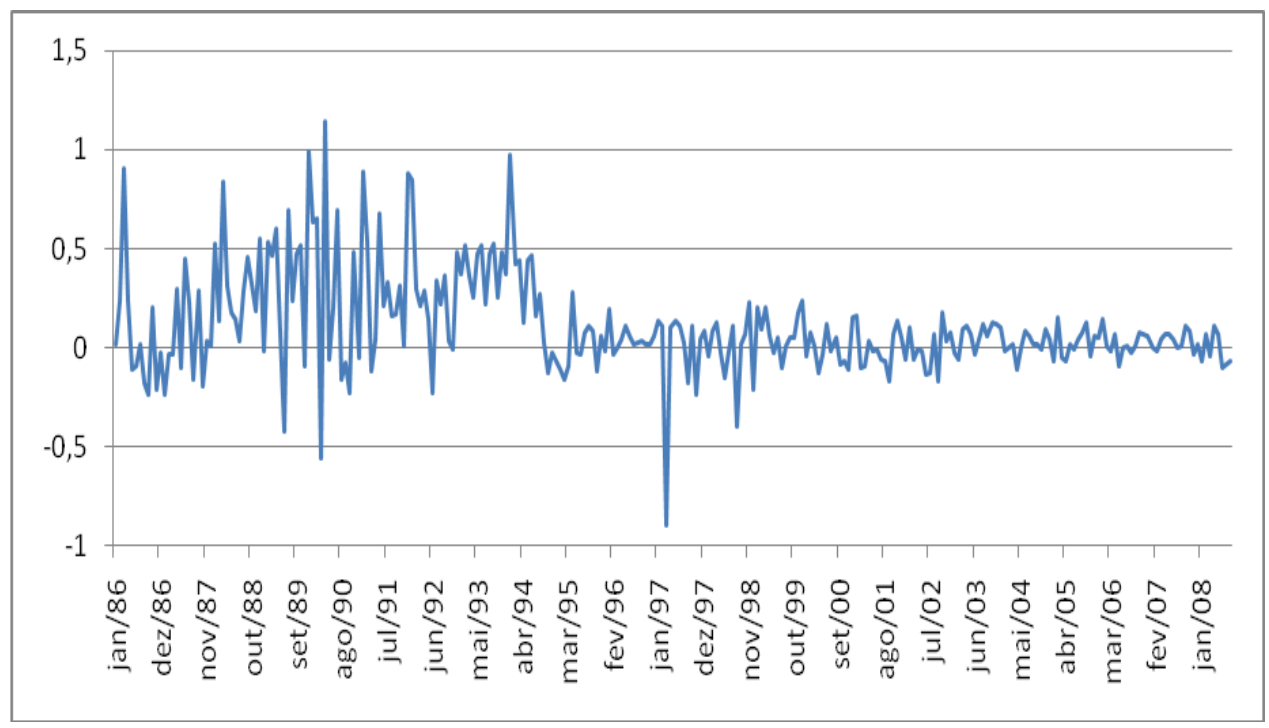

Figura 4.1 - Retornos mensais do Ibovespa desde 1986. 
Foram utilizados três horizontes de períodos para a análise das medidas de dispersão. Em uma primeira análise, utiliza-se todo o histórico obtido, de 1986 até o período de composição do portfólio ótimo. Nos demais casos, foram considerados horizontes menores, de 10 e 5 anos respectivamente, procurando calcular os desvios apenas em um passado mais recente. Essa diferenciação nos horizontes de tempo considerado é feita para fundamentar melhor a proposta, visto que o mercado brasileiro adquiriu maior estabilidade a partir de 1994, com início do plano real, e esta estabilidade vem crescendo desde 2004, que marca o início do novo mercado. Como se pode observar na Figura 4.1, o retorno mensal do Ibovespa possui grande instabilidade entre 1986 e 1994, motivando o uso de diferentes horizontes de tempo para o cálculo da dispersão dos cenários.

Sendo assim, quando se consideram todas as medidas de dispersão e todos os horizontes de períodos abordados, são propostos nove critérios de ponderação. Na Tabela 4.2, são apresentados os desvios utilizando os períodos até dezembro de 2004. Os desvios dos cenários para os anos seguintes podem ser obtidos de maneira análoga.

Tabela 4.1 - Medidas de dispersão dos retornos mensais até dez/2004.

\begin{tabular}{|c|c|c|c|c|c|c|c|c|c|c|c|c|c|}
\hline & & Jan & Fev & Mar & $A b r$ & Mai & Jun & Jul & Ago & Set & Out & Nov & Dez \\
\hline \multirow{3}{*}{$\begin{array}{l}\text { Desvio } \\
\text { Padrão }\end{array}$} & Desde 86 & 0,37 & 0,24 & 0,41 & 0,29 & 0,21 & 0,23 & 0,23 & 0,20 & 0,22 & 0,20 & 0,17 & 0,31 \\
\hline & 10 anos & 0,12 & 0,09 & 0,31 & 0,08 & 0,08 & 0,08 & 0,07 & 0,15 & 0,11 & 0,12 & 0,09 & 0,11 \\
\hline & 5 anos & 0,09 & 0,11 & 0,08 & 0,09 & 0,04 & 0,08 & 0,08 & 0,07 & 0,14 & 0,09 & 0,04 & 0,02 \\
\hline \multirow{3}{*}{ Variância } & Desde 86 & 0,13 & 0,06 & 0,17 & 0,08 & 0,05 & 0,05 & 0,05 & 0,04 & 0,05 & 0,04 & 0,03 & 0,10 \\
\hline & 10 anos & 0,01 & 0,01 & 0,09 & 0,01 & 0,01 & 0,01 & 0,01 & 0,02 & 0,01 & 0,01 & 0,01 & 0,01 \\
\hline & 5 anos & 0,01 & 0,01 & 0,01 & 0,01 & 0,00 & 0,01 & 0,01 & 0,00 & 0,02 & 0,01 & 0,00 & 0,00 \\
\hline \multirow{3}{*}{$\begin{array}{l}\text { Desvio } \\
\text { Absoluto } \\
\text { da Média }\end{array}$} & Desde 86 & 0,29 & 0,19 & 0,28 & 0,20 & 0,15 & 0,17 & 0,17 & 0,15 & 0,17 & 0,15 & 0,12 & 0,24 \\
\hline & 10 anos & 0,10 & 0,07 & 0,17 & 0,07 & 0,06 & 0,06 & 0,06 & 0,11 & 0,08 & 0,08 & 0,07 & 0,07 \\
\hline & 5 anos & 0,07 & 0,09 & 0,06 & 0,07 & 0,03 & 0,05 & 0,07 & 0,05 & 0,11 & 0,07 & 0,03 & 0,02 \\
\hline
\end{tabular}

Visando atribuir probabilidades maiores aos cenários com menor dispersão, considerase que os valores de $p_{t}$ para $t=1, \ldots, T_{c}$ representando os cenários, são inversamente 
proporcionais ao valor de dispersão medida no cenário, denotada por $\lambda_{t}$. Em outras palavras, definem-se as probabilidades de cada cenário como:

$$
p_{t}=\frac{K}{\lambda_{t}}, \quad t=1, \ldots, T_{c}
$$

Na equação (4.1), $K$ é uma constante de proporcionalidade, válida para todos os cenários $t$. Como a soma das probabilidades dos cenários deve ser igual a 1 (100\%), o valor de $K$ é dado por:

$$
K=\frac{1}{\sum_{t=1}^{T_{c}} \frac{1}{\lambda_{t}}}
$$

e o valor de $p_{t}$ é dado por:

$$
p_{t}=\frac{1}{\lambda_{t}} \cdot \frac{1}{\sum_{t k=1}^{T_{c}} \frac{1}{\lambda_{t k}}}, \quad t=1, \ldots, T_{c}
$$

A equação (4.3) fornece as ponderações utilizadas para cada cenário. Neste trabalho, como os cenários considerados são os meses do ano, $T_{c}=12$. Como é vantajoso utilizar um horizonte de períodos maior do que este número de cenários foi feita uma normalização para se obter a probabilidade de cada período. Dessa forma, todos os períodos pertencentes a dado cenário possuem a mesma probabilidade de ocorrência, que deve ser proporcional à probabilidade de ocorrência de seu cenário. As Figuras 4.2 e 4.3 ilustram as diferenças entre alguns dos critérios sugeridos. 


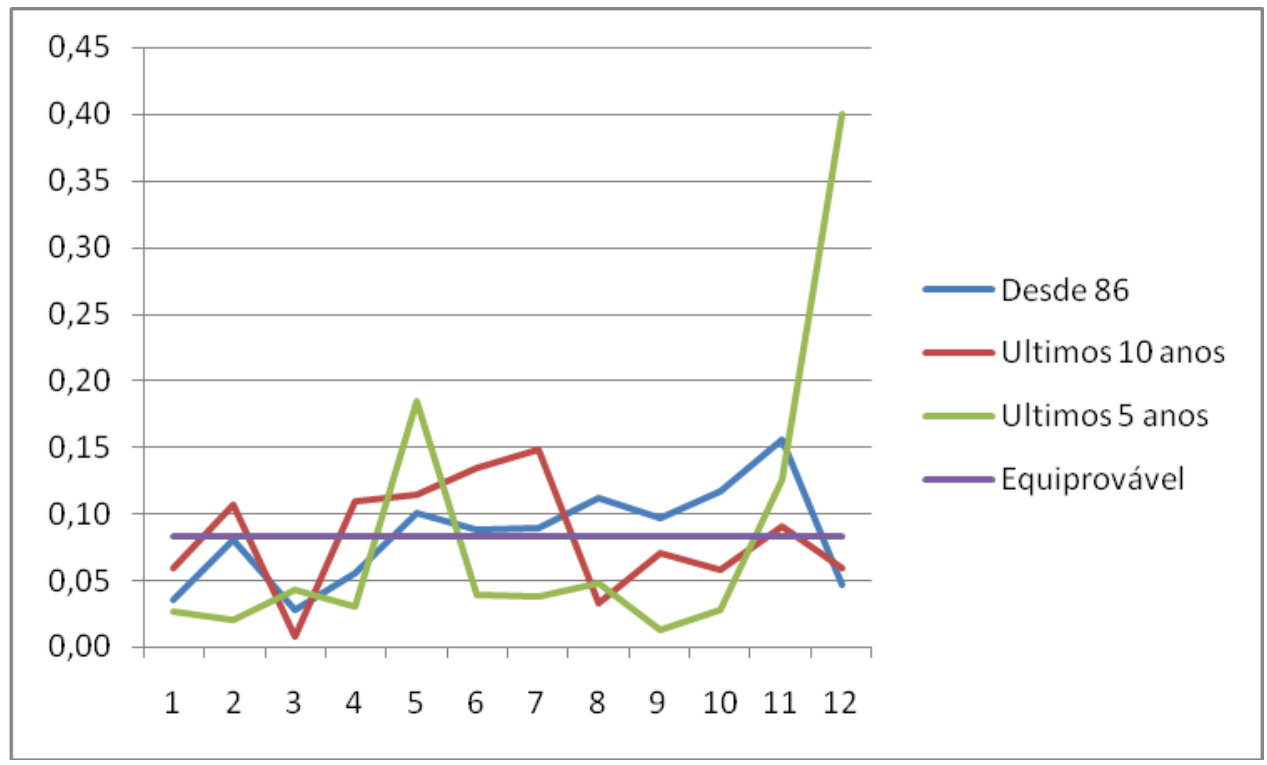

Figura 4.2 - Probabilidade dos cenários utilizando a variância para as faixas de período sugeridas.

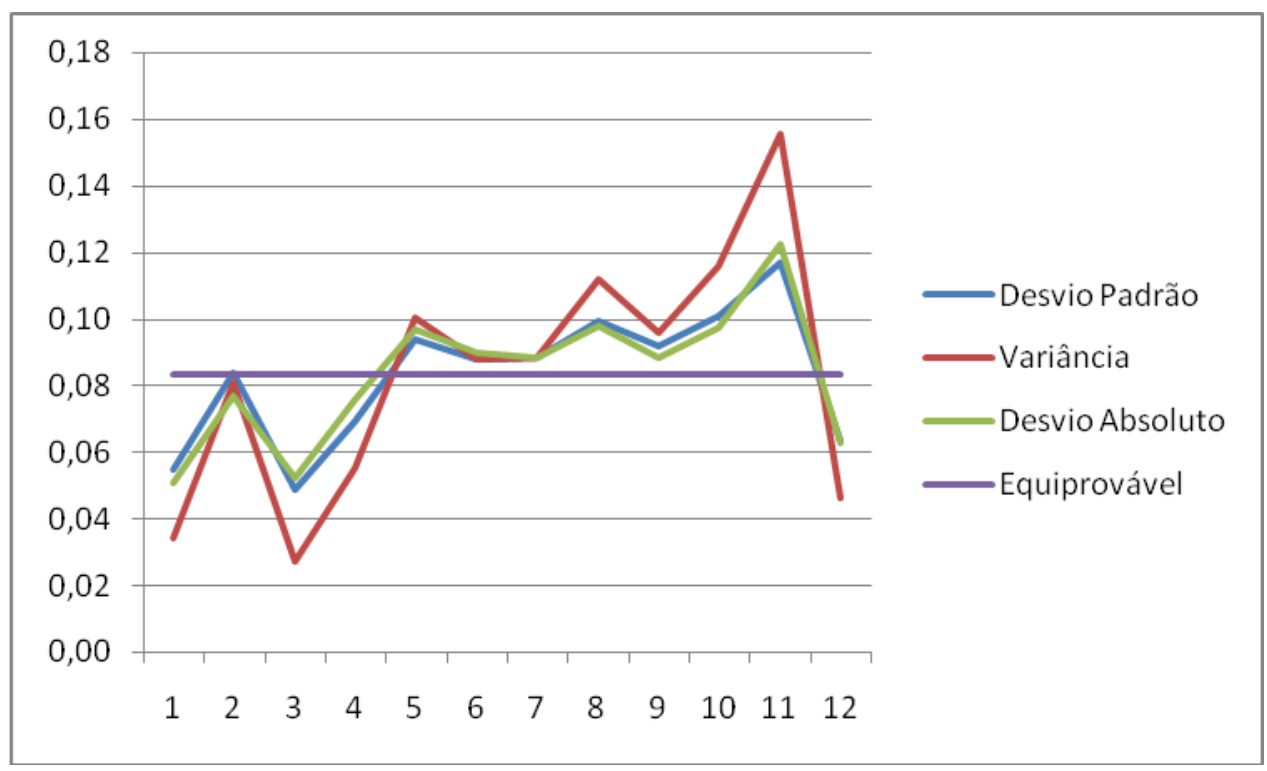

Figura 4.3 - Probabilidade dos cenários utilizando as três medidas de disperção, considerando os períodos desde 1986.

Os valores de probabilidade podem então ser utilizados para o cálculo do valor esperado do retorno da ação, representado por $r_{j}=E\left[R_{j}\right]=\sum_{t=1}^{T} p_{t} r_{j t}$ para cada ativo $j$ candidato a entrar na carteira. Utilizando cenários equiprováveis, este seria calculado como a média dos retornos no período. No caso dos modelos $M A D$ e $M S$, estes pesos também são 
utilizados na função objetivo, que calcula o risco baseado nos riscos de cada período, ao qual está associada uma probabilidade de ocorrência.

\subsection{Dados e Resultados Computacionais}

Testes computacionais foram realizados para comparar a qualidade das carteiras geradas a partir do modelo $M S$. Este modelo foi escolhido baseado em resultados preliminares (Albuquerque et al., 2008, ver Apêndice 1) em que foram avaliadas as ponderações do desvio padrão para os modelos lineares apresentados na Seção 3.2. Os melhores resultados foram obtidos para os experimentos em que se utilizou a relaxação do modelo $M S$.

Para elaborar os casos de teste, foram levantados os retornos mensais, desde 1994, dos ativos pertencentes aos índices IGC e Ibovespa no segundo trimestre de 2008, a partir dos quais foram organizados seis grupos de testes, que variavam o número de períodos e o número de ativos considerados. Enquanto o Ibovespa é o melhor indicador do desempenho do mercado brasileiro, o índice $I G C$ contém as ações de empresas que aderem às chamadas boas práticas de governança corporativa, que visam, por exemplo, proporcionar maior transparência a os agentes envolvidos com a empresa e minimizar a assimetria de informação existente entre administradores e proprietários. A adoção de tais práticas comumente significa a utilização de padrões de conduta superiores aos exigidos pela lei, ou pela regulamentação da própria $C V M$ (Comissão de Valores Mobiliários).

Na seleção de ativos candidatos a comporem a carteira ótima, foram considerados três grupos de teste: um contendo apenas as ações do índice $I G C$, outro contendo apenas as ações do Ibovespa e um terceiro contendo todas as ações selecionadas. Na seleção dos períodos selecionados, foram considerados dois grupos de teste: o primeiro abrangendo os retornos 
desde 1994, e o segundo desde 2000. Para que um ativo fosse adicionado a um problema em qualquer grupo de teste, este deveria ter sido negociado em ao menos $90 \%$ dos períodos considerados. O número de ativos considerados nos problemas varia de 31 a 92.

Em cada grupo de teste (seis no total) foram avaliados 43 períodos, de janeiro de 2005 a julho de 2008, sendo que foram obtidas dez carteiras ótimas em cada período: uma para cada método de ponderação de cenários (incluindo cenários equiprováveis). $\mathrm{O}$ desempenho das carteiras foi testado para os períodos após sua elaboração até agosto de 2008. Foi considerado o limite de $\mathrm{R} \$ 100.000,00$ para o investimento.

Inicialmente, foram propostos retornos mínimos de $25 \%$ e $50 \%$ a mais que a taxa de juros SELIC. Entretanto, testes preliminares mostraram que o primeiro dos níveis de retorno mínimo é muito conservador, visto que o retorno esperado do portfólio sempre era muito maior que esse valor. Por essa razão, não foram feitos testes distintos para os dois níveis de retorno requerido, e apenas o segundo foi utilizado. Não se consideraram limites na quantia máxima de investimento em ativos individuais, haja vista as suas implicações no método de solução, discutidas na Seção 3.3.

O método de solução (Seção 3.3) foi implementado em linguagem $C++$, com o uso das bibliotecas do CPLEX. Na obtenção das soluções dos problemas relaxados bem como dos subproblemas gerados a partir do problema original, foram utilizados, respectivamente o método Simplex e o Branch-and-Cut da versão 11.0 do CPLEX.

Os resultados são resumidos nas Tabelas 4.2 a 4.4. Cada tabela representa um dos grupos de ações selecionados, sendo esses divididos em duas partes: a primeira considera o histórico do grupo de ações desde 1994 e a segunda considera apenas o histórico desde 2000. Foi utilizada a seguinte notação para a ponderação dos cenários: $P$ - $d$ representa que a ponderação utiliza todos os retornos do Ibovespa disponíveis para o cálculo do desvio, isto é, 
desde 1986, ao passo que $P-10$ considera apenas os retornos dos 10 últimos anos e $P-5$ considera apenas dos últimos cinco anos. As tabelas mostram, para cada método de ponderação utilizado: a média dos valores obtidos para retornos esperados (denotado por $E[R]$ ), riscos, valores de objetivo (no caso do objetivo escolhido, representa retorno esperado menos o risco) e retorno efetivo (denotado por $E f[R]$ ); a mediana dos retornos efetivos e o erro médio, marcado como a distância entre o valor da função objetivo e retorno efetivo dos portfólios gerados para os 43 períodos considerados. Os valores são todos apresentados em porcentagem. São destacados (sublinhados e em negrito) os maiores valores de média e mediana dos retornos efetivos em cada grupo de teste, e são marcadas em cinza as amostras que superaram o método equiprovável tanto na média como na mediana.

Nos conjuntos de testes utilizados, a ponderação que utiliza a variância como medida de dispersão com a ponderação $P$ - $d$ mostrou-se a mais eficiente em termos de retorno efetivo médio, se destacando sobre todas as outras métricas adotadas nos quatro grupos de teste com melhores resultados (Tabelas 4.2 e 4.3), somente ficando abaixo dos cenários equiprováveis no grupo de teste que considera apenas as ações do Ibovespa para o investimento, com histórico tomado a partir de 2000, grupo que apresentou o pior desempenho em termos de retornos efetivos comparado com os demais. Em geral, as medidas que utilizaram todo o histórico disponível no cálculo de probabilidades $(P-d)$ apresentaram resultados melhores (em termos de média e mediana) em relação ao uso dos cenários equiprováveis, com resultados superiores em quatro grupos de teste para o uso do desvio absoluto da média como medida de dispersão (Tabelas 4.3 e 4.4), e cinco para o uso do desvio padrão e da variância. 
Tabela 4.2 - Desempenho das carteiras geradas no grupo de experimentos que contém todas as ações selecionadas para a análise.

\begin{tabular}{|c|c|c|c|c|c|c|c|c|}
\hline & \multirow{2}{*}{\multicolumn{2}{|c|}{ Ponderação }} & \multicolumn{4}{|c|}{ Média } & \multicolumn{2}{|c|}{ Mediana Erro } \\
\hline & & & $E[R]$ & Risco & Obj & Ef[R] & $E f[R]$ & Médio \\
\hline \multirow{10}{*}{$\begin{array}{l}1 \\
9 \\
9 \\
4\end{array}$} & \multicolumn{2}{|c|}{ Equiprováveis } & 5,40 & 3,63 & 1,77 & 1,90 & 2,06 & 0,13 \\
\hline & \multirow{3}{*}{$\begin{array}{l}\text { Desvio } \\
\text { Absoluto } \\
\text { da Média } \\
\end{array}$} & $P-d$ & 4,99 & 3,27 & 1,72 & 1,89 & 2,74 & 0,17 \\
\hline & & P-10 & 5,11 & 3,37 & 1,74 & 1,95 & 2,38 & 0,21 \\
\hline & & P-05 & 5,31 & 3,48 & 1,83 & 2,05 & 2,40 & 0,22 \\
\hline & \multirow{3}{*}{$\begin{array}{l}\text { Desvio } \\
\text { Padrão }\end{array}$} & $P-d$ & 5,04 & 3,31 & 1,73 & $\overline{1,92}$ & $\underline{2,79}$ & 0,19 \\
\hline & & P-10 & 5,21 & 3,45 & 1,76 & 1,88 & 2,24 & 0,13 \\
\hline & & P-05 & 5,28 & 3,46 & 1,82 & 2,01 & 1,90 & 0,19 \\
\hline & & $P-d$ & 4,82 & 3,11 & $\overline{1,72}$ & 2,09 & 2,75 & 0,37 \\
\hline & \multirow[t]{2}{*}{ Variância } & P-10 & 5,06 & 3,28 & 1,78 & 1,80 & 2,33 & 0,02 \\
\hline & & P-05 & 5,46 & 3,33 & 2,13 & 1,88 & 1,95 & $-0,26$ \\
\hline & \multicolumn{2}{|c|}{ Equiprováveis } & 4,15 & 2,27 & 1,88 & 1,43 & 2,56 & $-0,45$ \\
\hline \multirow{9}{*}{$\begin{array}{l}2 \\
0 \\
0 \\
0\end{array}$} & \multirow{3}{*}{$\begin{array}{l}\text { Desvio } \\
\text { Médio } \\
\text { Absoluto }\end{array}$} & $P-d$ & 4,44 & 2,47 & 1,96 & 1,73 & 2,43 & $-0,23$ \\
\hline & & $P-10$ & 4,51 & 2,53 & 1,98 & 1,30 & 2,36 & $-0,68$ \\
\hline & & P-05 & 4,90 & 2,75 & 2,15 & 1,23 & 1,77 & $-0,92$ \\
\hline & \multirow{3}{*}{$\begin{array}{l}\text { Desvio } \\
\text { Padrão }\end{array}$} & P-d & 4,38 & 2,43 & 1,95 & 1,70 & 2,34 & $-0,25$ \\
\hline & & $P-10$ & 4,53 & 2,56 & 1,98 & 1,47 & 3,02 & $-0,50$ \\
\hline & & P-05 & 4,91 & 2,76 & 2,15 & 1,17 & 1,54 & $-0,98$ \\
\hline & \multirow{3}{*}{ Variância } & $P-d$ & 4,71 & 2,64 & 2,08 & 1,95 & 2,57 & $-0,13$ \\
\hline & & P-10 & 4,97 & 2,84 & 2,13 & 1,47 & 3,39 & $-0,66$ \\
\hline & & P-05 & 6,16 & 3,30 & 2,86 & 1,27 & 1,87 & $-1,59$ \\
\hline
\end{tabular}

Tabela 4.3 - Desempenho das carteiras geradas no grupo de experimentos que contém as ações do $I G C$.

\begin{tabular}{|c|c|c|c|c|c|c|c|c|}
\hline & \multirow{2}{*}{\multicolumn{2}{|c|}{ Ponderação }} & \multicolumn{4}{|c|}{ Média } & \multicolumn{2}{|c|}{ Mediana Erro } \\
\hline & & & $E[R]$ & Risco & Obj & $\operatorname{Ef}[R]$ & $\mathrm{Ef}[\mathrm{R}]$ & Médio \\
\hline \multirow{10}{*}{$\begin{array}{l}1 \\
9 \\
9 \\
4\end{array}$} & \multicolumn{2}{|c|}{ Equiprováveis } & 5,46 & 3,72 & 1,74 & 1,98 & 1,65 & 0,24 \\
\hline & \multirow{3}{*}{$\begin{array}{l}\text { Desvio } \\
\text { Absoluto } \\
\text { da Média }\end{array}$} & $P-d$ & 5,07 & 3,39 & 1,68 & 2,09 & 2,14 & 0,41 \\
\hline & & $P-10$ & 5,16 & 3,46 & 1,70 & 2,08 & 2,60 & 0,39 \\
\hline & & P-05 & 5,39 & 3,59 & 1,81 & 1,96 & 2,57 & 0,16 \\
\hline & \multirow{3}{*}{$\begin{array}{l}\text { Desvio } \\
\text { Padrão }\end{array}$} & $P-d$ & 5,11 & 3,42 & 1,69 & 2,07 & 1,94 & 0,39 \\
\hline & & $P-10$ & 5,26 & 3,55 & 1,71 & 1,83 & 1,94 & 0,12 \\
\hline & & P-05 & 5,35 & 3,55 & 1,80 & 2,12 & 2,63 & 0,32 \\
\hline & \multirow{3}{*}{ Variância } & $P-d$ & 4,89 & 3,22 & 1,67 & 2,20 & 2,66 & 0,52 \\
\hline & & $P-10$ & 5,10 & 3,38 & 1,72 & 1,86 & 1,89 & 0,14 \\
\hline & & P-05 & 5,49 & 3,38 & 2,11 & 1,93 & $\underline{3,15}$ & $-0,18$ \\
\hline \multirow{10}{*}{$\begin{array}{l}2 \\
0 \\
0 \\
0\end{array}$} & \multicolumn{2}{|c|}{ Equiprováveis } & 4,08 & 2,21 & 1,87 & 1,40 & 2,28 & $-0,47$ \\
\hline & \multirow{3}{*}{$\begin{array}{l}\text { Desvio } \\
\text { Absoluto } \\
\text { da Média } \\
\end{array}$} & $P-d$ & 4,39 & 2,45 & 1,95 & 1,59 & 2,29 & $-0,36$ \\
\hline & & $P-10$ & 4,48 & 2,51 & 1,97 & 1,19 & 2,66 & $-0,78$ \\
\hline & & P-05 & 4,83 & 2,70 & 2,13 & 1,35 & 2,00 & $-0,78$ \\
\hline & \multirow{3}{*}{$\begin{array}{l}\text { Desvio } \\
\text { Padrão }\end{array}$} & $P-d$ & 4,32 & 2,38 & 1,93 & 1,60 & 2,80 & $-0,34$ \\
\hline & & $P-10$ & 4,48 & 2,52 & 1,97 & 1,31 & 2,76 & $-0,66$ \\
\hline & & P-05 & 4,83 & 2,70 & 2,13 & 1,29 & 2,05 & $-0,85$ \\
\hline & \multirow{3}{*}{ Variância } & $P-d$ & 4,67 & 2,62 & 2,05 & 1,96 & 2,85 & $-0,10$ \\
\hline & & $P-10$ & 4,93 & 2,82 & 2,11 & 1,57 & 3,02 & $-0,55$ \\
\hline & & P-05 & 6,02 & 3,20 & 2,83 & 1,13 & 1,87 & $-1,69$ \\
\hline
\end{tabular}


Tabela 4.4 - Desempenho das carteiras geradas no grupo de experimentos que contém as ações do Ibovespa.

\begin{tabular}{|c|c|c|c|c|c|c|c|c|}
\hline & & & & Méc & & & Mediana & Erro \\
\hline & Ponder: & ação & $E[R]$ & Risco & Obj & Ef[R] & Ef[R] & Médio \\
\hline & Equiprov & áveis & 4,90 & 3,81 & 1,10 & 1,64 & 1,32 & 0,55 \\
\hline & Desvio & P-d & 4,85 & 3,77 & 1,08 & 1,70 & 1,75 & 0,62 \\
\hline & Absoluto & P-10 & 5,00 & 3,86 & 1,14 & 1,70 & 1,59 & 0,56 \\
\hline 1 & da Média & P-05 & 4,82 & 3,70 & 1,12 & 1,76 & 1,13 & 0,64 \\
\hline 9 & & P-d & 4,84 & 3,76 & 1,08 & 1,73 & 1,78 & 0,65 \\
\hline 0 & Desvi & P-10 & 5,01 & 3,86 & 1,15 & 1,61 & 1,35 & 0,46 \\
\hline 4 & & P-05 & 4,84 & 3,72 & 1,12 & 1,77 & 1,24 & 0,65 \\
\hline & & P-d & 4,74 & 3,66 & 1,08 & 1,76 & 2,47 & 0,68 \\
\hline & Variância & P-10 & 5,07 & 3,86 & 1,21 & 1,61 & 2,51 & 0,40 \\
\hline & & P-05 & 5,19 & 3,76 & 1,44 & 1,71 & 2,57 & 0,27 \\
\hline & Equiprov & áveis & 3,44 & 2,86 & 0,58 & 1,24 & 0,70 & 0,67 \\
\hline & Desvio & $P-d$ & 3,51 & 2,86 & 0,65 & 1,43 & 1,00 & 0,78 \\
\hline & Absoluto & P-10 & 3,36 & 2,75 & 0,61 & $\overline{1,20}$ & 0,15 & 0,59 \\
\hline 2 & da Média & P-05 & 4,48 & 3,52 & 0,96 & 1,13 & 0,90 & 0,16 \\
\hline 0 & & $P-d$ & 3,56 & 2,90 & 0,65 & 1,33 & 1,01 & 0,67 \\
\hline 0 & 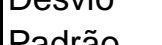 & P-10 & 3,17 & 2,61 & 0,56 & 1,07 & 0,31 & 0,50 \\
\hline 0 & & P-05 & 4,54 & 3,56 & 0,98 & 1,18 & 0,35 & 0,20 \\
\hline & & P-d & 3,68 & 2,90 & 0,78 & 1,05 & 1,20 & 0,27 \\
\hline & Variância & P-10 & 2,94 & 2,35 & 0,59 & 0,74 & 0,26 & 0,15 \\
\hline & & P-05 & 6,01 & 4,19 & 1,82 & 1,26 & $-0,46$ & $-0,56$ \\
\hline
\end{tabular}

O bom desempenho da ponderação pela variância pode estar relacionado à propriedade de acentuar os valores de probabilidade, tanto para baixo nos cenários mais instáveis, como para cima nos casos estáveis (Figura 4.3). Incorporando mais retornos que as outras medidas, a ponderação P-d pôde representar melhor o período consecutivo ao de criação do portfólio, talvez como conseqüência do uso de mais observações para seu cálculo (tornando-a a ponderação mais estável), ou mesmo pela melhor representação do cenário.

Também se pode observar que quando é considerado um número menor de períodos para a composição da carteira ótima, o desempenho médio e mediano dos casos de teste decai, o que não é sempre verdadeiro para a redução no número de ativos. Ao passo que ao se considerar apenas ativos do índice Ibovespa as carteiras mostraram grande queda no desempenho, motivado talvez pelo pouco número de ativos disponíveis no período considerado para análise, o grupo de teste considerando apenas ativos do IGC obteve 
resultados melhores em termos de retorno efetivo médio do que os que consideravam todos os ativos em vários casos, tanto em termos de média como de mediana.

A Figura 4.4 ilustra o capital acumulado pelo investidor ao longo dos 43 períodos de investimento, admitindo-se que este possui R $\$ 100.000,00$ de capital disponível no primeiro período (janeiro de 2005), que sempre realiza o investimento feito em cada período, e que sempre invista essa mesma quantia em um portfólio de ações a cada período. É observado o comportamento de portfólios gerados de quatro maneiras em cada período, que diferem no grupo de ativos considerado em sua composição (separados nos que consideram ativos do $I G C$ e Ibovespa, e que apenas considera ativos do $I G C$ ) e na forma de ponderação de cenários (separados pela utilização cenários equiprováveis e a ponderação de melhor resultado, com dispersão medida pela variância do grupo de períodos $P-d$ ). Os resultados para as carteiras geradas apenas com ações do Ibovespa não são ilustrados na figura por não terem apresentados bons resultados, como visto na Tabela 4.4. Para todos os períodos foi considerado o histórico das ações desde 1994, e o capital acumulado representa o capital inicial somado a todos os retornos obtidos pelas carteiras de períodos anteriores.

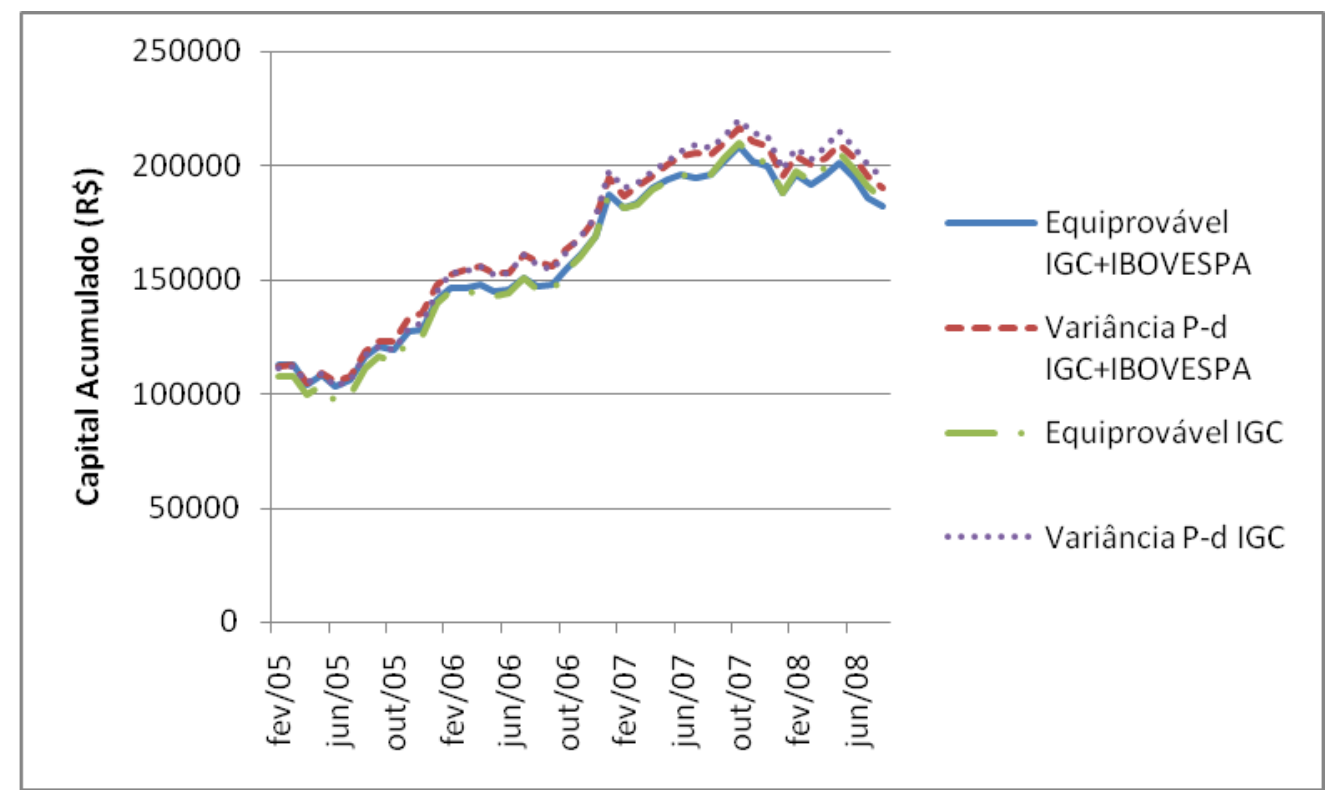

Figura 4.4 - Curvas de retorno acumulado alterando a carteira escolhida todos os períodos. 
Como se pode observar, houve um ganho quando se utilizou o método de ponderação de cenários em relação à utilização de cenários equiprováveis para os dois conjuntos de ações. Embora a restrição dos ativos apenas para aqueles pertencentes ao índice $I G C$ ter mostrado resultados tipicamente melhores, o ganho não é muito significativo, o que indica que aparentemente grande parte dos ativos é compartilhada por ambos os portfólios. Isso é uma conseqüência de o número de ações do $I G C$ ser muito grande proporcionalmente ao número de ações presentes apenas no Ibovespa, mostrando que grande parte das empresas estão adotando as boas práticas de governança corporativa. Embora tenha havido melhora, experimentos envolvendo um universo maior de ações deveria ser considerado na comparação com o IGC, de forma a confirmar os benefícios ao investidor pelas implicações das boas práticas de governança corporativa.

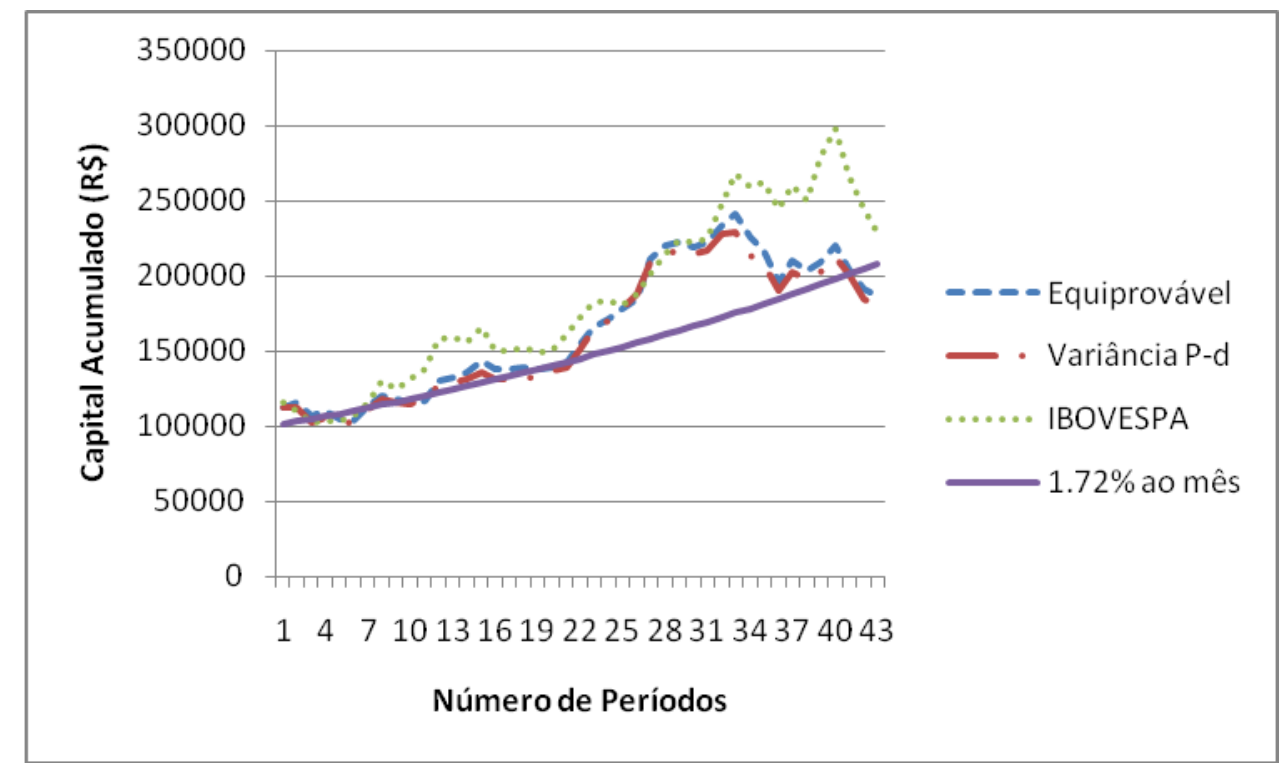

Figura 4.5 - Desempenho das carteiras geradas no primeiro período do grupo de problemas que considera todos os ativos na elaboração da carteira.

A fim de avaliar o desempenho do portfólio ao longo do tempo, foram utilizados os retornos efetivos dos ativos após a criação do portfólio, simulando assim seus resultados futuros. Como foram gerados os portfólios para 43 períodos, o desempenho do portfólio gerado no período $t$ foi medido nos $43-t$ próximos períodos. A Figura 4.5 ilustra os retornos 
acumulados dos portfólios gerados no primeiro período do grupo de testes que utiliza todos os ativos contabilizando seus retornos desde 1994.

Pode-se notar que o comportamento dos portfólios ao longo do tempo é muito semelhante entre si, obtendo valores de retornos acumulados muito próximos em quase todos os períodos. Além disso, o comportamento em longo prazo das carteiras mostra-se semelhante ao do Ibovespa, apenas acentuando as quedas, o que pode indicar um alto valor de beta da carteira escolhida, e por estarem sujeitas à taxa imposta sobre o retorno, as ascensões das carteiras se mostraram mais brandas do que as quedas. É importante considerar nesta análise o fato da carteira teórica do Ibovespa ser revista a cada quatro meses, explicando parcialmente o comportamento relativo das carteiras com o índice. Como os períodos analisados presenciaram um grande momento para o mercado nacional, exceto nos últimos períodos, foi possível, em longo prazo, superar o retorno mínimo exigido de 1,72\%.

É importante notar que o intuito desta análise é comparar o comportamento da carteira em relação ao desempenho do mercado e não realizar uma comparação entre investimentos. No caso do investidor investir seu capital em todas as ações do Ibovespa, mantendo suas devidas proporções no índice, a taxa sobre o retorno (imposto de renda) também deveria ser considerada. Neste caso, os estudos mostraram que o investidor que aplicasse seu capital no índice possuiria, ao final dos períodos, um retorno acumulado menor.

A Figura 4.6 ilustra os resultados para as carteiras geradas somente com as ações do $I G C$. Os resultados mostram que as carteiras escolhidas no primeiro período apresentaram resultados melhores em relação às carteiras da Figura 4.5 em longo prazo, sendo que o uso da ponderação de cenários para este experimento mostrou-se superior para a grande maioria dos períodos, chegando a ficar acima do valor do Ibovespa em alguns meses. 


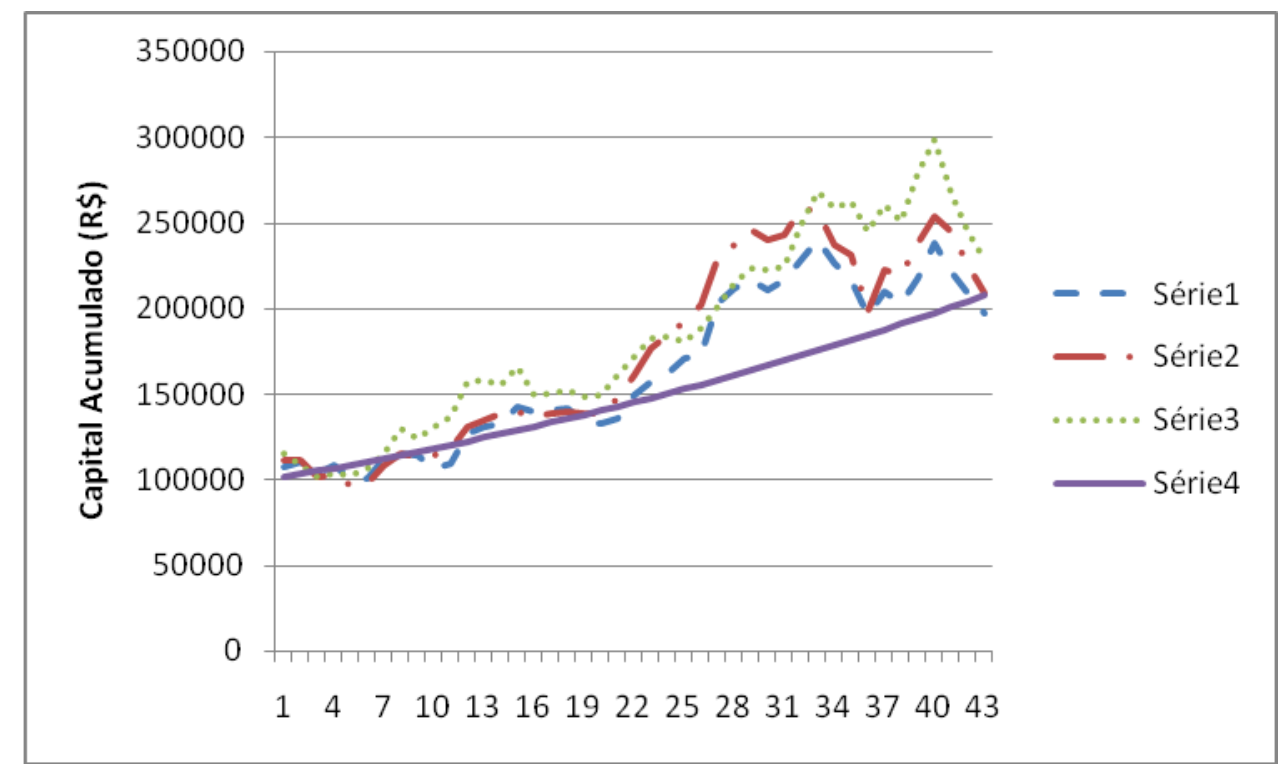

Figura 4.6 - Desempenho das carteiras geradas no primeiro período do grupo de problemas que considera os ativos do $I G C$.

Quando se comparam a Figura $4.4 \mathrm{com}$ as Figuras 4.5 e 4.6 , nota-se que ao se modificar o portfólio constantemente, o comportamento da curva passa a apresentar maior estabilidade, obtendo ascensões e quedas mais suaves em relação ao comportamento das demais carteiras e do Ibovespa. Isso pode ser um indicativo de que, ao custo de modificar o portfólio periodicamente, o investidor consegue obter maior controle de seus investimentos em longo prazo. Um estudo mais detalhado seria necessário para averiguar qual a periodicidade ideal para se alterar a composição da carteira para que esta ainda assim atingisse seus objetivos e mantivesse certo nível de estabilidade. Outra abordagem possível seria o estudo do problema de escolha ótima de portfólios multi-períodos, que considera os períodos posteriores à criação da carteira.

Também foi analisada a taxa de retorno dos portfólios, considerando os períodos após sua criação. Nessa análise, foram tomados os portfólios gerados em todos os períodos (de janeiro de 2005 a julho de 2008) pelos dois grupos de experimentos com melhores resultados (utilizando todos os retornos históricos disponíveis dos grupos de ações do $I G C$ e das ações do IGC e Ibovespa), escolhidos utilizando-se cenários equiprováveis e ponderados pela 
variância do grupo de períodos $P-d$. As taxas de retorno de cada portfólio foram calculadas tendo como base o capital acumulado no último período, ou seja, agosto de 2008. Os resultados são apresentados na Figura 4.7.

Mais uma vez a queda acentuada sofrida pelas curvas se deve aos períodos finais da análise, visto que houve uma queda brusca no mercado devido à crise econômica, e os portfólios que foram gerados mais próximos à esses períodos (isso é, os pontos mais à direita do gráfico) não obtiveram observações suficientes em períodos estáveis ou de ascenção para atingir um desempenho tal que imunizasse o portfólio da crise. Cabe também a observação de que quanto mais à direita do gráfico, menos observações foram utilizadas para calcular a taxa de retorno mensal do portfólio, implicando em maior erro nas medições.

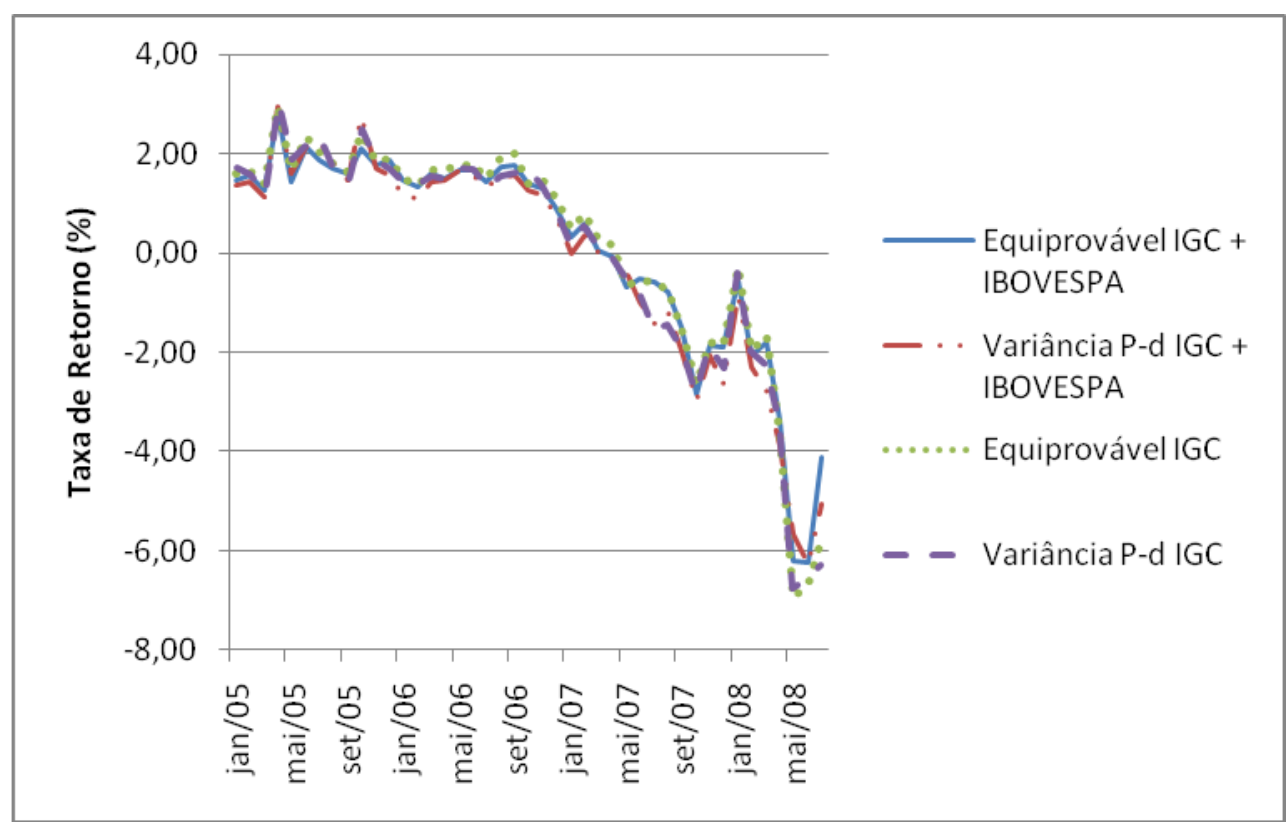

Figura 4.7 - Taxas mensais de retorno observadas em agosto de 2008 para cada portfólio gerado.

A figura ilustra que, apesar dos resultados terem indicado que a restrição de retorno mínimo era muito conservadora para os valores escolhidos $(25$ e $50 \%$ a mais que a taxa SELIC), esses valores (aproximadamente 1,43 e 1,72\% respectivamente) só puderam ser atingidos ou superados em longo prazo para os portfólios gerados antes de janeiro de 2007. 
Apesar da crise financeira ser certamente um dos fatores que colaboraram para esse cenário, a medida de segurança adotada na função objetivo mostrou-se uma estimativa de retorno muito mais acurada. Sendo assim, a exigência de um nível de retorno esperado para o portfólio pode ser distorcida em longo prazo.

\subsection{Conclusões}

A metodologia utilizada para a ponderação de cenários mostrou grande potencial na obtenção de portfólios com melhor desempenho no período de geração do mesmo. Quando o desempenho é traçado ao longo do tempo, no entanto, o comportamento dos portfólios tende a ser mais equilibrado, não havendo grande distinção entre os resultados. Uma possível justificativa para esse comportamento é o fato dos valores de probabilidade mudarem sempre que uma nova observação torna-se disponível. Quando se gera um portfólio e analisa-se seu resultado em um período, os valores de probabilidade de cada cenário estão bem representados, e resultam em comportamentos melhores na média e mediana. Entretanto, como o portfólio não é recalculado a cada período, esse ganho pode não ser tão efetivo com o passar dos períodos.

Outro ponto importante na ponderação é a escolha do melhor método para o cálculo das probabilidades. Para o mercado brasileiro, a ponderação pela variância de todos os retornos do Ibovespa desde 1986 mostrou-se o melhor critério, mas pela impossibilidade de executar novos testes utilizando mercados internacionais, não se pode afirmar se este é de fato o melhor critério de ponderação para todos os casos. Recomenda-se que um estudo prévio seja feito, de forma a avaliar qual medida deve ser empregada. 
Em resumo, com base apenas nos resultados discutidos neste trabalho, pode-se dizer que a ponderação de cenários é mais indicada a investidores interessados em investir em curto prazo. Uma possível nova aplicação é um método para a re-otimização do portfólio escolhido, sempre que os valores de probabilidade de ocorrência dos cenários deixarem de corresponder ao período em que o portfólio foi escolhido, ou em problemas de otimização de carteira de ações multi-período. 


\section{Capítulo 5 - Modelo Proposto e Curva de Pareto}

A análise de longo prazo das carteiras geradas no Capítulo 4 indica um comportamento que acentua as variações de acordo com o resultado do mercado. Os experimentos mostraram que as carteiras deveriam ser constantemente modificadas para ter um comportamento mais estável. Nos períodos de queda do Ibovespa, os portfólios gerados pelo método $M S$ tipicamente apresentaram grande queda no desempenho, o que resultou, em muitos casos, no não atendimento do retorno mensal mínimo requerido pelo investidor, em curto ou em longo prazo. Estes fatos indicam que as carteiras geradas pelo método $M S$, mesmo utilizando diferentes métricas para a ponderação dos cenários, apresentam um alto valor de risco não-diversificável.

Esse comportamento motivou a proposta de algumas alterações do modelo $M S$, visando melhorar o desempenho dos portfólios ótimos em períodos de queda do mercado e em longo prazo. Neste capítulo, também é proposta uma nova abordagem de resolução do problema, cujo objetivo é gerar um conjunto de carteiras eficientes para diversas faixas de risco e de retorno. Para tanto, são geradas curvas de Pareto, que permitem que o investidor escolha a carteira que melhor satisfaça seus interesses.

Em resumo, este capítulo possui dois objetivos: propor alterações do modelo $M S$ e apresentar um procedimento para gerar diferentes carteiras eficientes. 


\section{1 - Modelagem proposta}

As alterações propostas têm como alvo o risco não-diversificável, o objetivo é dar ao investidor maior controle sob sua carteira, levando em consideração na modelagem do problema mais uma componente de seu comportamento em relação ao mercado. Além disso, também se procura reduzir o risco diversificável da carteira, impondo um número mínimo de ativos a serem selecionados pela carteira escolhida.

Ao abordar os tipos de risco dessa forma, espera-se que, ao escolher a carteira ótima, esta esteja sujeita a um menor risco real em situações nas quais o desempenho do mercado é ruim.

O novo modelo proposto ( $M B$ - Modelo Beta) é uma adaptação do modelo de Speranza e Mansini (2005) e é dado por:

$$
\begin{array}{lll}
\operatorname{Max} & \sum_{j \in N}\left[(1-g) r_{j} s_{j} x_{j}-c_{j} z_{j}\right]-\sum_{t=1}^{T} p_{t} y_{t} & \\
\text { s.a: } & y_{t} \geq \sum_{j \in N}\left(r_{j}-r_{j t}\right) s_{j} x_{j} & t=1, \ldots, T \\
& \sum_{j \in N}\left[(1-g) r_{j} s_{j} x_{j}-c_{j} z_{j}\right] \geq \mu_{0} \sum_{j \in N} s_{j} x_{j} & \\
& \sum_{j \in N} s_{j} x_{j} \leq C & \\
& \sum_{j \in N}\left(\beta_{\max }-\beta_{j}\right) s_{j} x_{j} \geq 0 & \\
& \sum_{j \in N}\left(\beta_{j}-\beta_{\min }\right) s_{j} x_{j} \geq 0 & \\
& \sum_{j \in N} z_{j} \geq k & j \in N \\
& l_{j} z_{j} \leq x_{j} \leq u_{j} z_{j} & t=1, \ldots, T \\
& y_{t} \geq 0 & j \in N \\
& x_{j} \in Z_{+} & j \in N \\
& z_{j} \in\{0,1\} &
\end{array}
$$


A função objetivo, juntamente com as restrições (5.2) a (5.4), e (5.9) a (5.11), são as mesmas do modelo $M S$, assim como os dados do problema e variáveis de decisão. Nas restrições (5.5) e (5.6), $\beta_{\min }$ e $\beta_{\max }$ são, respectivamente, o valor mínimo e máximo que o beta da carteira pode possuir e $\beta_{j}$ representa o beta do ativo $j$. Os betas dos ativos individuais são contabilizados segundo a quantidade de capital investido no ativo. As duas restrições em conjunto limitam a escolha de portfólios, permitindo que apenas aqueles que estiverem dentro dos limites impostos sejam selecionados. A restrição (5.7) impõe que o portfólio possua pelo menos $k$ ações. A restrição (5.8), por sua vez, faz com que as variáveis $x$ possuam um limite mínimo e máximo de investimento.

Com as alterações propostas, o método de solução proposto em Mansini e Speranza (2005), apresentado no Capítulo 3, perde grande parte da sua eficiência. Entre as possíveis razões estão: a falha no pressuposto original de que a carteira ótima para o problema inteiro possui apenas ativos cujo custo relativo é suficientemente pequeno na solução relaxada; as dificuldades de se estimar esse subconjunto de ativos em casos onde as variáveis possuem limites mínimos e máximos (discutido no Capítulo 3); e a dificuldade de se obter uma solução inicial através da heurística de busca local, visto que não há garantias de que as soluções heurísticas encontradas sejam factíveis.

Uma vez que o modelo proposto trata de novos fatores que representam os interesses do investidor, optou-se por utilizar um método de solução que apresentasse várias opções de carteiras de ações, representando uma curva de Pareto em termos de risco e de retorno para o problema. O novo método de solução é descrito como segue. 


\section{2 - Método de Solução}

O problema de escolha ótima de portfólio, assim como diversos outros na literatura, é um problema multi-objetivo. Vários trabalhos consideraram diferentes maneiras de se definir a função objetivo apropriada ao problema em termos de retorno e de risco. No entanto, a aplicação de funções que consideram ambos os objetivos deve lidar com informações a priori sobre a preferência do tomador de decisões. A medida de segurança maximizada no modelo $M S$ é um exemplo disso: para gerar portfólios distintos para diferentes perfis de investidores, deveriam ser considerados diferentes pesos para o risco e para o retorno na função objetivo do problema.

Uma abordagem diferente reside na aceitação de vários critérios de avaliação de uma carteira eficiente e em gerar um conjunto dessas carteiras. Os resultados seriam análogos à fronteira eficiente apresentada no Capítulo 2, que possui o conjunto das melhores carteiras para cada faixa de risco ou de retorno, o que não torna viável classificar uma solução como melhor do que a outra. A esse conjunto de soluções se atribui o nome de soluções não dominadas ou soluções Pareto-ótimas. Apenas após a fase de geração das carteiras a tomada de decisão é feita, visto que o investidor tem acesso ao espaço das melhores soluções para escolher a que melhor represente seus interesses.

Essa abordagem pode ser empregada não apenas na escolha de portfólios ótimos, mas também em outros tipos de problemas multi-objetivos com objetivos conflitantes. Por exemplo, em Doerner et al. (2004) e Doerner et al. (2006) é considerado o problema de escolha ótima de uma carteira de projetos, que é solucionado utilizando a metaheurística Colônia de Formigas para traçar a curva de Pareto. Em Reddy e Kumar (2007), os autores utilizam a metaheurística enxame de partículas para gerar a curva de Pareto em problemas de 
controle de reservatórios. Em ambos os trabalhos, argumenta-se que a geração da curva de Pareto pelos métodos usuais de otimização é muito custosa computacionalmente, visto que o método de solução deve ser aplicado iterativamente ao problema, e por isso são utilizados outros métodos de solução. No entanto, o uso dos métodos tradicionais de otimização inteiramista mostrou-se viável na resolução do problema estudado. Além disso, como o problema da escolha de portfólio ótimo possui apenas dois objetivos, um número menor de exemplares deve ser resolvido a cada iteração, sendo que a solução da iteração passada fornece limitantes para a solução seguinte, fazendo com que as iterações finais demandem menor custo computacional. O método utilizado para obter a curva de Pareto é desenvolvido a seguir.

\section{Método Curva de Pareto}

Passo 1. Substitua a função objetivo de $M B$ para a maximização do retorno:

$$
\sum_{j \in N}\left[(1-g) r_{j} s_{j} x_{j}-c_{j} z_{j}\right]
$$

Resolva o problema de otimização. Armazene o valor da função objetivo em $h_{x}^{+}$.

Passo 2. Encontrando o portfólio de menor risco para o nível de retorno $h_{x}{ }^{+}$:

- Substitua a função objetivo do modelo para a minimização do risco: $\sum_{t=1}^{T} p_{t} y_{t}$;

- Adicione a restrição: $\sum_{j \in N}\left[(1-g) r_{j} s_{j} x_{j}-c_{j} z_{j}\right]=h_{x}^{+}$;

- Resolva o problema de otimização. Armazene em $x^{+}$a solução encontrada.

Passo 3. Substitua a função objetivo do problema $M B$ original para a minimização do risco: $\sum_{t=1}^{T} p_{t} y_{t}$; 
Resolva o problema de otimização. Armazene o valor da função objetivo em $h_{y}$.

Passo 4. Encontrando o portfólio de maior retorno para o nível de risco $h_{y}$ :

- Substitua a função objetivo do modelo para a maximização do retorno: $\sum_{j \in N}\left[(1-g) r_{j} s_{j} x_{j}-c_{j} z_{j}\right]$;

- Adicione a restrição: $\sum_{t=1}^{T} p_{t} y_{t}=h_{y}$;

- Resolva o problema de otimização. Armazene em $x^{0}$ a nova solução encontrada. Armazene o custo da solução em $h_{x}{ }^{0}$.

Passo 5. Faça:

$$
\varepsilon=\frac{\left(h_{x}^{+}-h_{x}^{0}\right)}{m}, i=1 \text { e } h_{x}=h_{x}^{0}
$$

\section{Passo 6. Enquanto $h_{x}{ }^{(i-1)}<h_{x}^{+}$faça:}

- Faça $h_{x}=h_{x}^{(i-1)}+\varepsilon$;

- $M B=M B \cup \sum_{j \in N}\left[(1-g) r_{j} s_{j} x_{j}-c_{j} z_{j}\right] \geq h_{x}$;

- Resolva o problema de otimização (minimização do risco, como no Passo 3). Armazene o valor da função objetivo em $h_{y}{ }^{(i)}$;

- Encontre o portfólio de maior retorno para o nível de risco $h_{y}{ }^{(i)}$ (como feito no Passo 4);

- Armazene em $x^{(i)}$ a nova solução encontrada. Armazene o custo da solução em $h_{x}^{(i)}$.

- Atualize o contador $i$.

\section{Fim enquanto.}


Os Passos de 1 a 4 encontram as soluções dos extremos da curva de Pareto, ou seja, a solução que possui o menor nível de risco e a solução com o maior nível de retorno. No Passo 5, é definida a distância, em termos de retorno esperado, entre uma solução e a próxima. Considera-se que serão gerados portfólios para $m$ faixas de retorno. No Passo 6, incrementa-se o valor de retorno obtido na iteração passada e impõe-se esse valor como restrição de retorno exigido. Assim, a cada iteração são encontrados portfólios com maiores retornos, ao custo de riscos maiores.

\section{3 - Testes Computacionais}

Para realizar o teste de eficiência do método, foram utilizados os dados para os ativos referentes a três períodos: janeiro de 2007, janeiro de 2008 e julho de 2008. Estes períodos foram escolhidos, pois pertencem, respectivamente, a um período de ascensão, instabilidade e queda do mercado. Para as restrições adicionais, foram obtidos os valores dos betas mensais dos ativos para os períodos considerados, utilizando o software Economatica e os valores 0,8 e 1,2 foram utilizados para, respectivamente, os limites mínimos e máximos do beta da carteira. A idéia foi buscar carteiras que se comportem de forma semelhante ao mercado. $\mathrm{O}$ beta das ações foi obtido por meio de dois horizontes distintos: de 30 e de 60 períodos para o cálculo.

Foi considerado um limite mínimo de 8 ativos na carteira, sendo exigido que ao menos $1 \%$ do capital fosse investido em cada ativo. Essa resolução visa à diminuição do risco diversificável da carteira, sendo fundamentada em dois princípios: no fato de que esse número representa o número médio de ativos nos portfólios ótimos obtidos no Capítulo 4, menos uma 
margem de segurança de dois desvios padrões e no fato de que o ganho marginal no risco diversificável da carteira passaria a ser cada vez menor se muitos ativos fossem exigidos. $\mathrm{Na}$ prática, esse limite estabelecido só terá efeitos visíveis na construção de portfólios de alto retorno, visto que soluções que priorizem o risco serão naturalmente diversificadas. Para gerar uma curva de Pareto, também foi necessário considerar uma restrição a mais, que estabelece um valor mínimo de investimento de $99,5 \%$ do capital disponível. Essa medida foi obtida a partir da média e do desvio padrão do total investido nas soluções dos experimentos do Capítulo 4 de forma a gerar carteiras com níveis de investimento comparáveis àquelas já obtidas. Esta restrição se tornou necessária para os problemas em que o risco da carteira é minimizado (Passo 3 do método de solução), uma vez que uma carteira com risco nulo era uma solução factível para o problema. Vale destacar que a restrição de retorno exigido é calculada tendo por base o capital investido, então uma forma de se obter risco nulo é o investimento nulo.

A Figura 5.1 ilustra a curva de Pareto obtida para janeiro de 2008. Os retornos efetivos para esse mesmo período são apresentados na Figura 5.2.

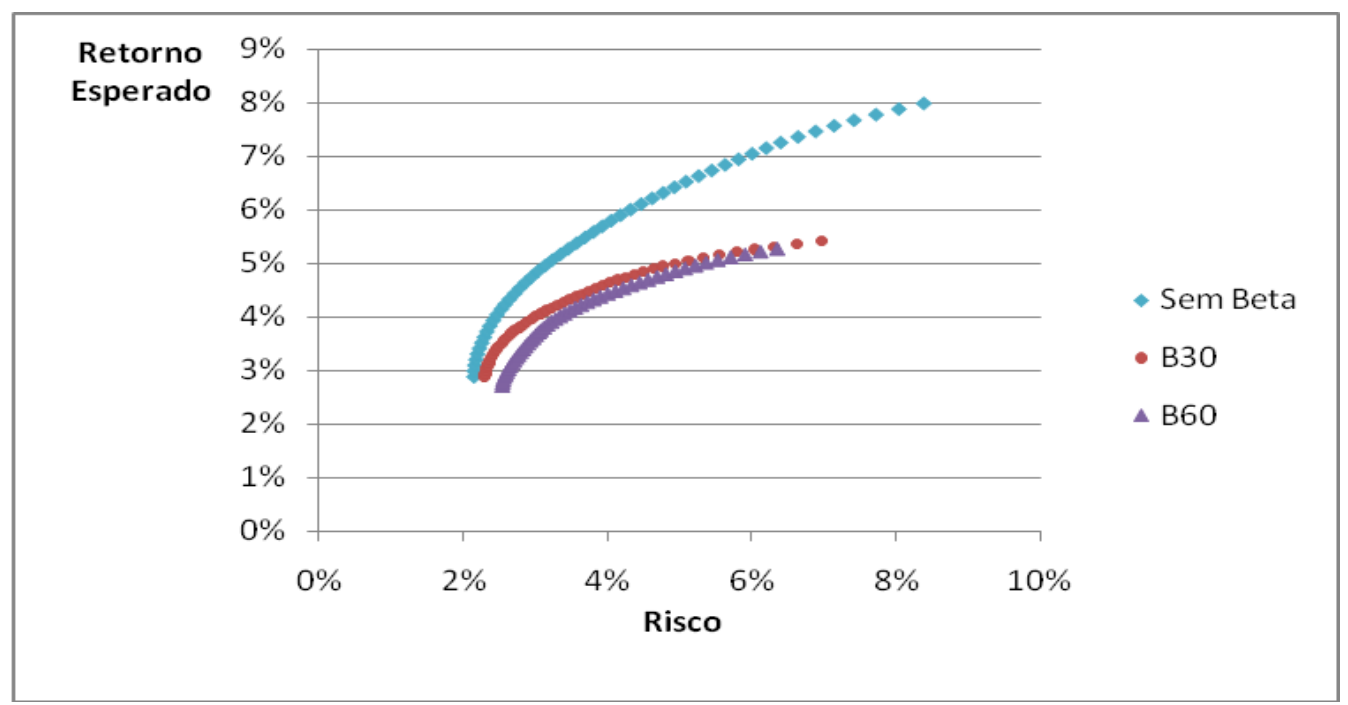

Figura 5.1 - Curvas de Pareto para experimento do período de jan/2007. 


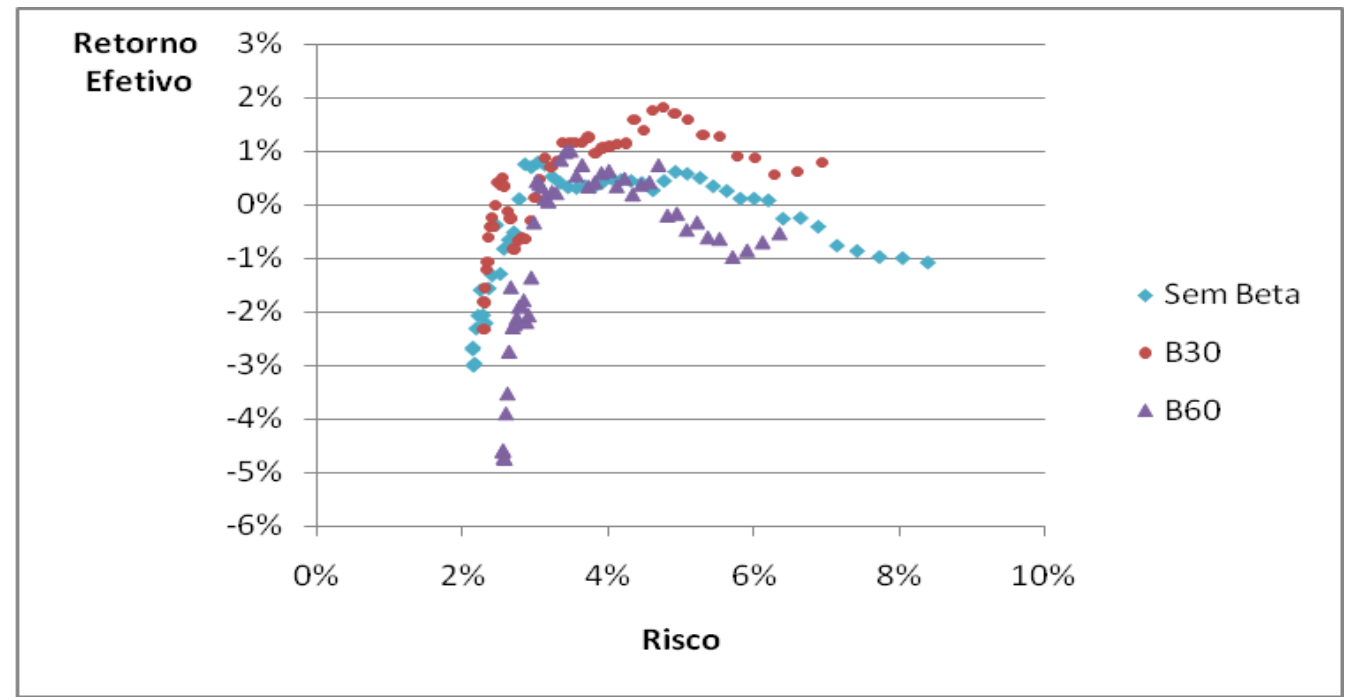

Figura 5.2 - Retornos efetivos pelos níveis de risco dos portfólios gerados em jan/2007.

Observando a curva de Pareto obtida, nota-se que as carteiras geradas pelo método sem considerar os valores de beta estão distribuídas em um intervalo maior de risco e de retorno. Isso se deve ao fato de que o problema resolvido possuía menor controle de risco da carteira, tanto diversificável quanto não-diversificável, ou seja, o problema é menos restrito e consegue obter maior retorno e menor risco.

O desempenho das carteiras geradas para o período mostra que ao considerar o beta calculado com base nos últimos 30 meses as carteiras obtidas tiveram retorno efetivo maior para a maioria das faixas de risco, ao passo que as carteiras que utilizavam o beta dos ativos calculados para os últimos 60 meses tiveram pior desempenho no período. Isso pode representar que os valores de beta dos ativos mudaram de forma que as observações anteriores ao horizonte de 30 meses distorceram o comportamento dos ativos em relação ao mercado para este período. No entanto, para se fazer essa afirmação, mais estudos seriam necessários.

As Figuras 5.3 e 5.4 ilustram, respectivamente, a curva de Pareto e os retornos efetivos para o período de janeiro de 2008 . 


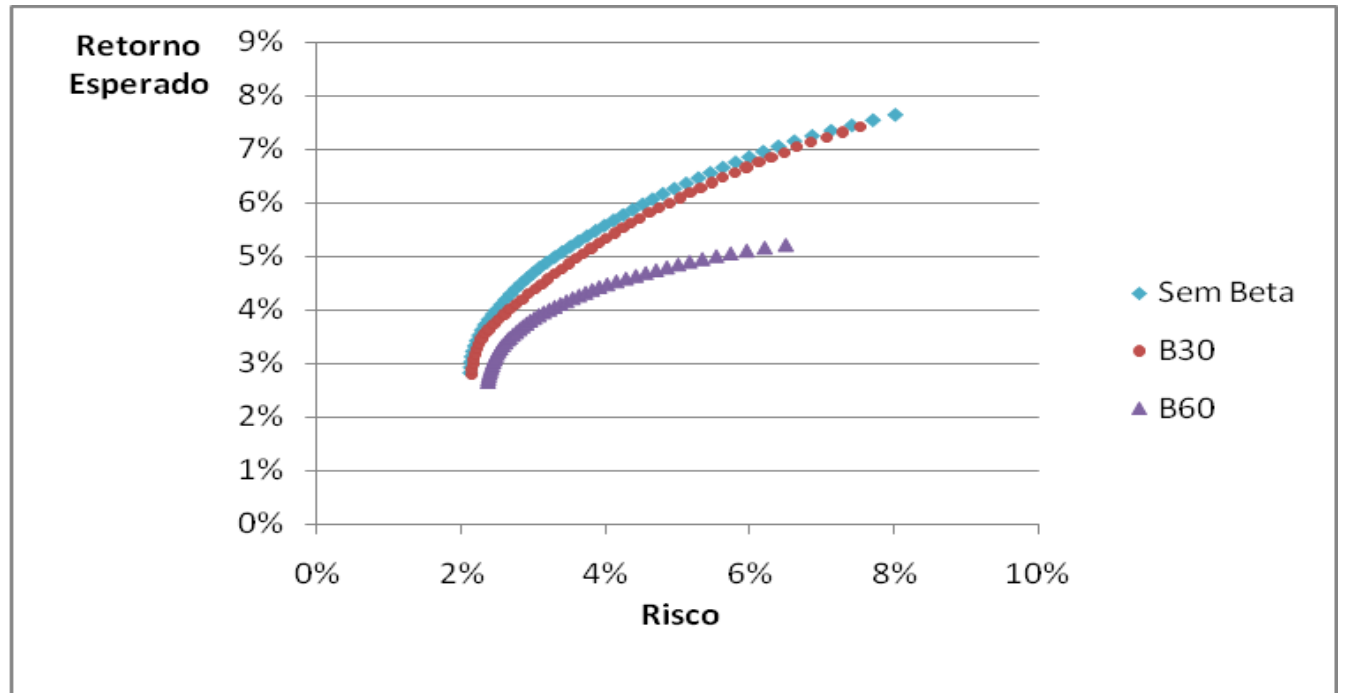

Figura 5.3 - Curvas de Pareto para experimento do período de jan/2008.

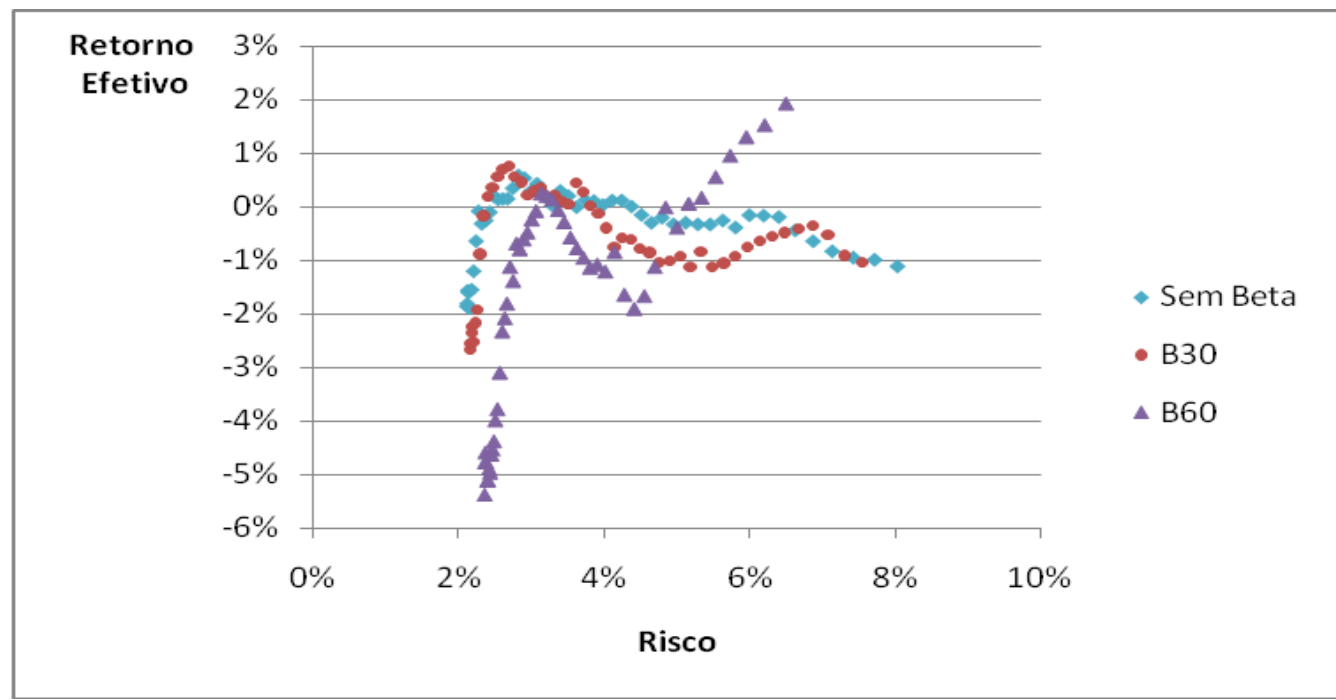

Figura 5.4 - Retornos efetivos pelos níveis de risco dos portfólios gerados em jan/2008.

Para o período analisado, nota-se que a diferença entre os valores de risco e retorno das carteiras geradas pelo método B30 e sem a utilização do beta diminuiu consideravelmente, indicando que as carteiras obtidas possuem valores de betas muito próximos. Ao se acompanhar o desempenho das mesmas no período, nota-se que as diferenças também diminuíram, sendo que não restringir o beta no período mostrou-se vantajoso. A utilização do método B60 mostra-se superior apenas para os níveis de risco acima de cerca de $5 \%$. 
As Figuras 5.6 e 5.7 são referentes aos resultados obtidos no período de julho de 2008. Este período em particular é importante à essa análise, visto que constitui um dos períodos onde os portfólios gerados no Capítulo 4 apresentaram os piores desempenhos. Neste período, o mercado brasileiro apresentou grande queda.

Observa-se que as curvas das carteiras sem beta e utilizando o beta de 30 meses diminuíram ainda mais sua diferença, sendo praticamente coincidentes para os níveis de risco abaixo de $4 \%$. Neste cenário, a eficiência observada das carteiras que utilizam o beta de 60 meses mostrou-se superior, indicando, possivelmente, que a composição do beta utilizando mais períodos tornou a medida mais precisa ao se considerar a crise financeira, visto que o beta de 30 meses atribui um peso maior aos períodos da crise A escolha de portfólios mais arriscados possibilitou, no período, a escolha de carteiras muito eficientes, com melhores níveis de retorno. Além disso, nota-se que os únicos portfólios a obterem retornos não negativos no período foram gerados restringindo o beta da carteira e utilizando o beta de 60 meses como medida.

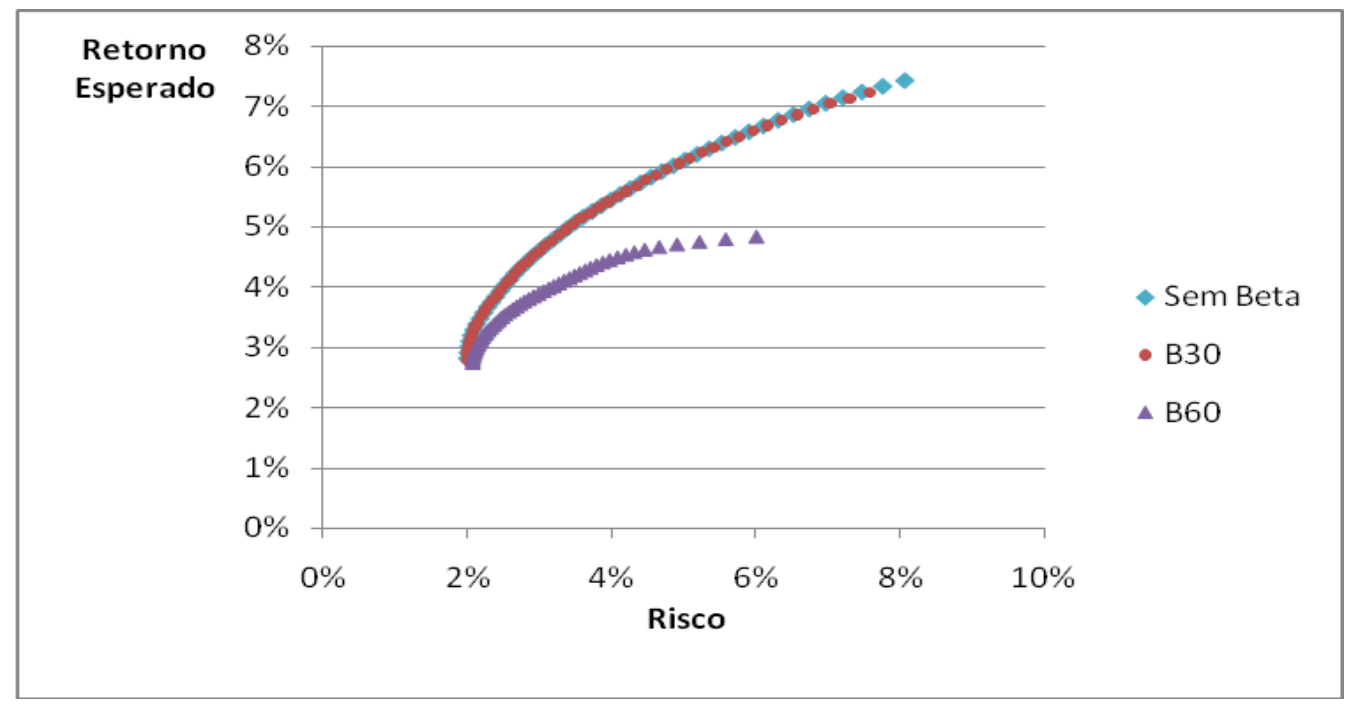

Figura 5.5 - Curvas de Pareto para experimento do período de jul/2008. 


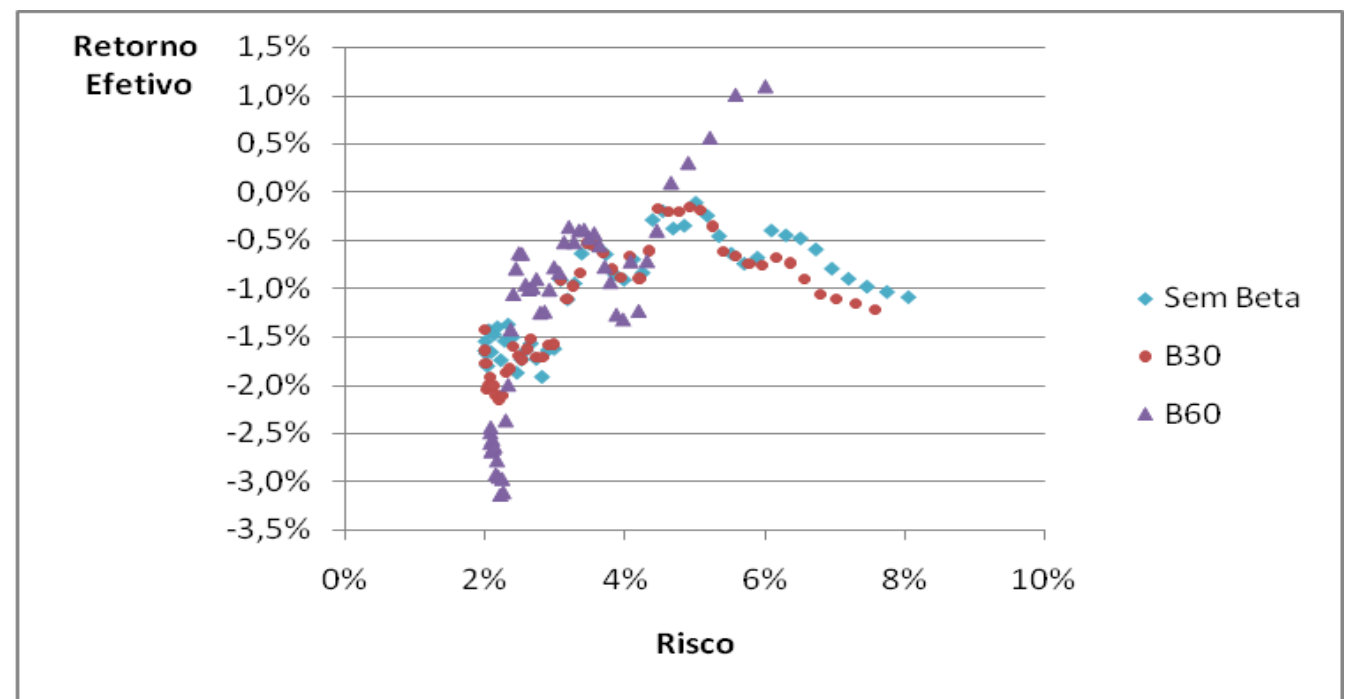

Figura 5.6 - Retornos efetivos pelos níveis de risco dos portfólios gerados em jul/2008.

Tendo em vista a crise financeira e a queda acentuada do Ibovespa, pode ser do interesse do investidor exigir de sua carteira um valor pequeno ou negativo de beta, para que o comportamento da carteira diminua as perdas no período ou, no melhor caso, efetue ganhos. Sendo assim, para a análise do período de julho de 2008, outras duas curvas de soluções foram geradas exigindo que o beta da carteira esteja na faixa de $-0,2$ e $+0,8$, sendo que o limite inferior foi obtido a partir do menor valor de beta observado em um ativo. Os resultados são apresentados nas Figuras 5.7 e 5.8.

Para este período, as carteiras que não consideram o beta e com beta de 30 meses tem diferença muito pequena. No entanto, as carteiras geradas ao restringir-se o beta obtiveram retornos efetivos melhores, sendo superiores àquelas geradas sem a restrição do beta em quase todas as faixas de risco. Assim como para a análise anterior, o cálculo do beta utilizando 60 meses mostrou-se mais eficiente. Suas soluções que priorizam o retorno esperado se beneficiaram por uma ação em particular, que não era o investimento principal em nenhuma outra carteira gerada no período, e, apresentando beta pequeno, foi um dos poucos ativos com 
alto retorno no período. Tolerando maiores níveis de risco, uma quantia maior deste ativo era comprada, o que resultou em maiores retornos efetivos nestes casos.

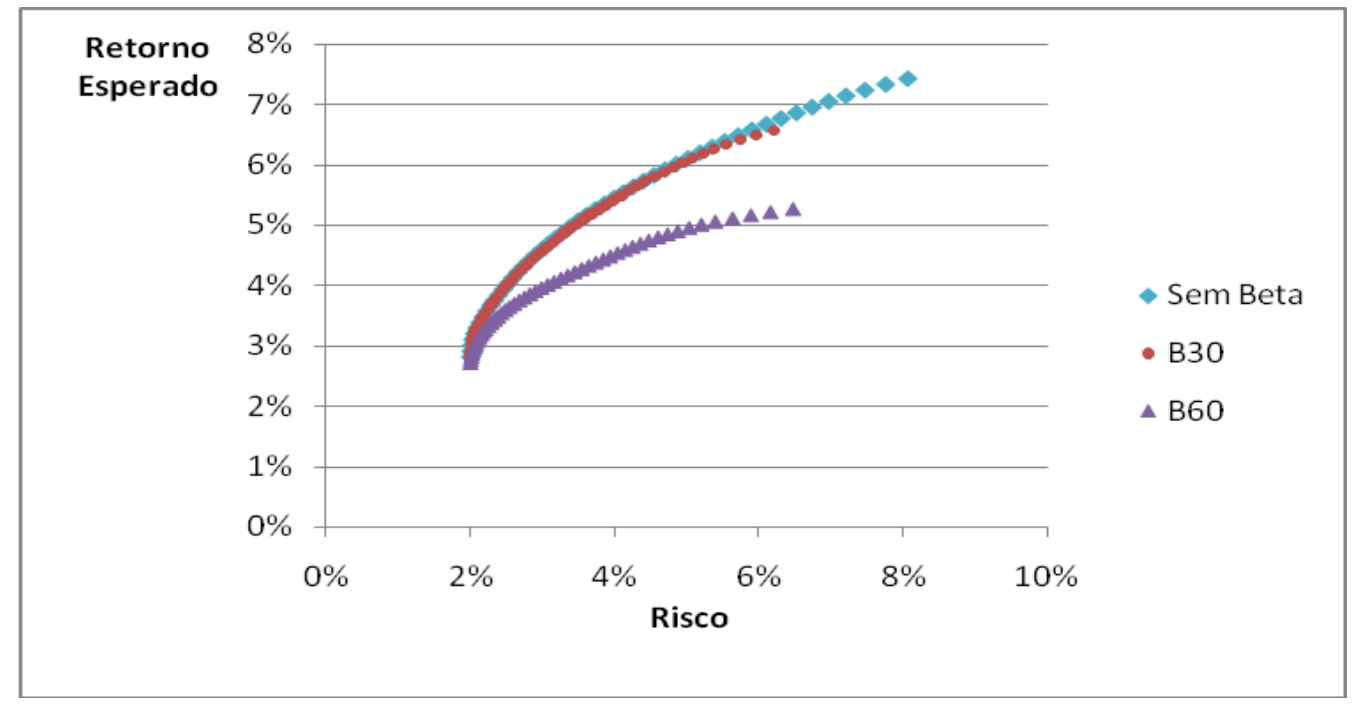

Figura 5.7 - Curvas de Pareto para experimento do período de jul/2008 exigindo níveis menores de beta.

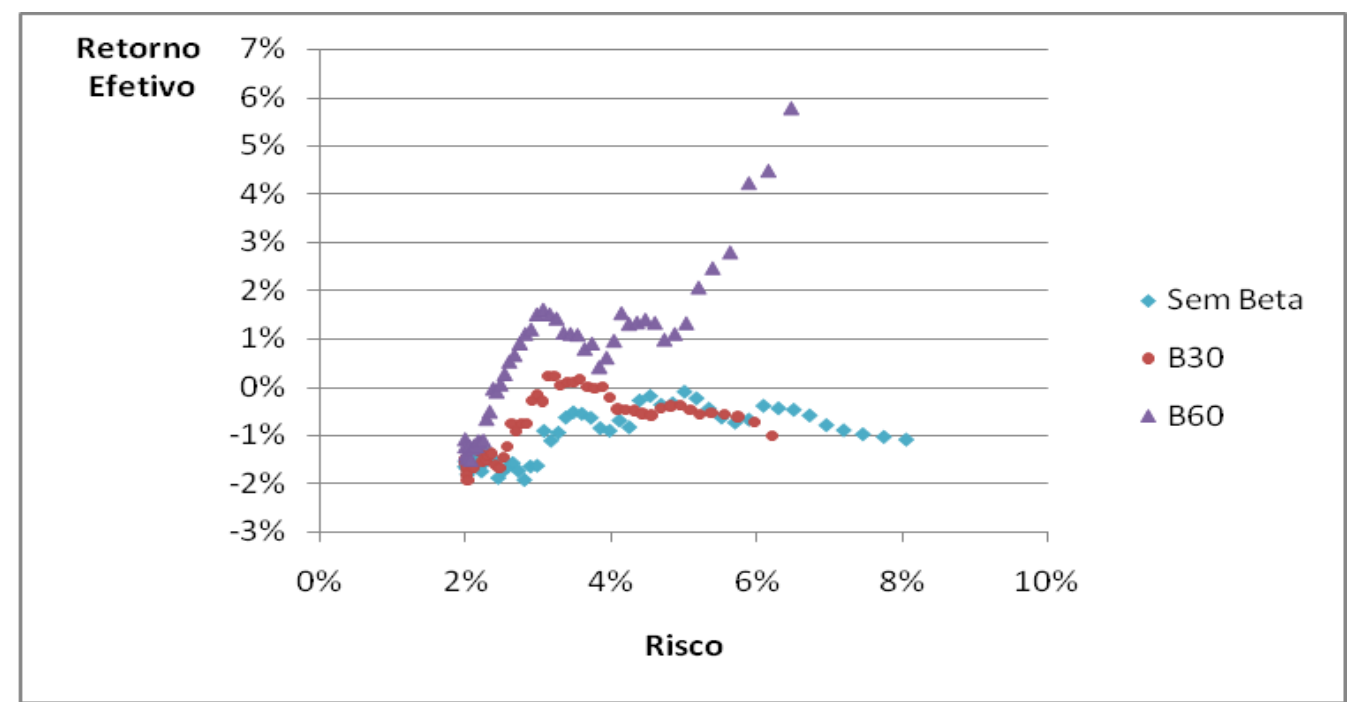

Figura 5.8 - Retornos efetivos pelos níveis de risco dos portfólios gerados em jul/2008 exigindo níveis menores de beta.

De forma geral, o desempenho das carteiras que priorizavam o risco foi inferior em todos os períodos. Esse fato pode ser um indicador de que o semi-desvio absoluto da média não é a medida de risco mais adequada em problemas de minimização do risco, sendo que passa a ser indicada nos casos em que o investidor tolere riscos mais altos. 


\section{4 - Análise do Comportamento da Carteira}

Para verificar o comportamento das carteiras em que se restringe o beta nos períodos seguintes à sua geração, foram escolhidas aquelas com o melhor valor da função objetivo segundo o modelo $M S$, ou seja, com o maior valor da medida de segurança. Foram computados os retornos efetivos da carteira após o período de criação e o valor da curva em cada período representa o retorno acumulado atingido pela carteira no período. Na Figura 5.9 são apresentadas as curvas referentes aos portfólios do primeiro período da análise, ou seja, janeiro de 2007.

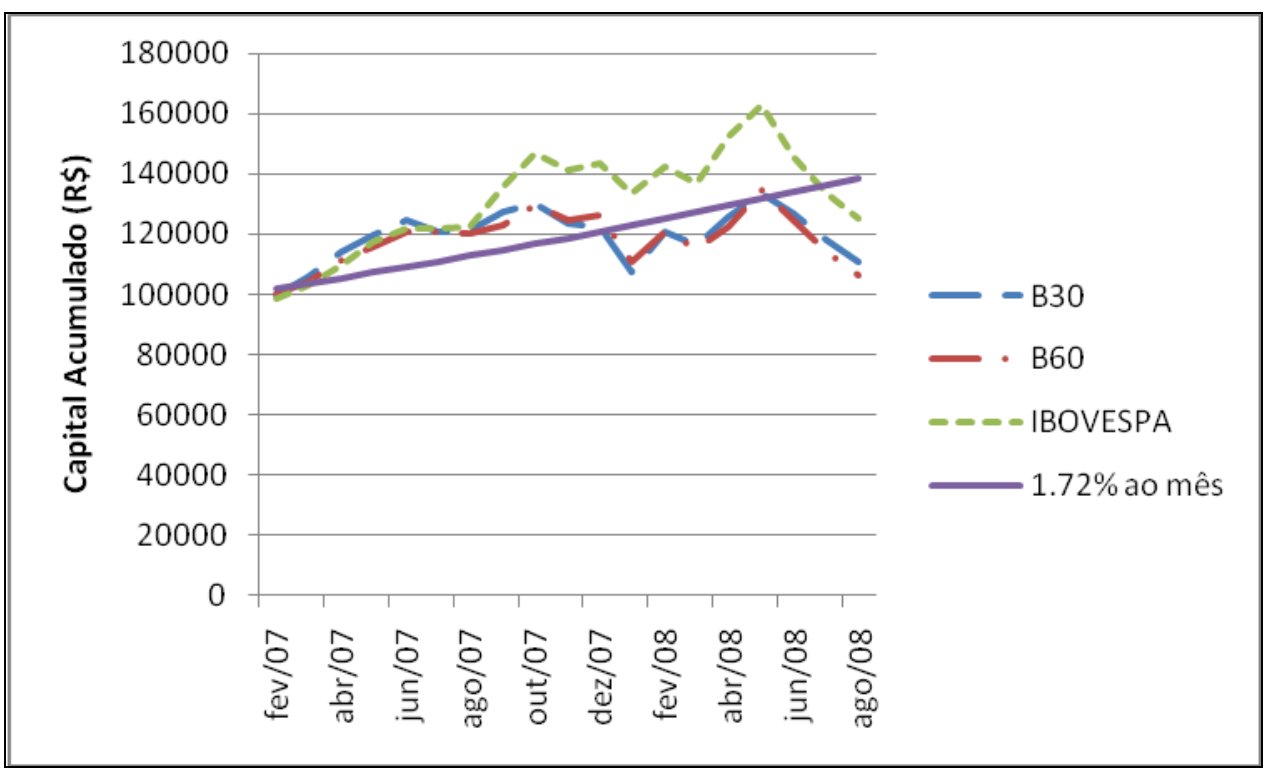

Figura 5.9 - Desempenho das carteiras geradas em jan/2007 utilizando o beta.

Como se pode observar, o comportamento das carteiras que utilizam o beta torna-se inferior ao do Ibovespa com o passar do tempo. Ainda assim, é possível obter retornos maiores que o exigido $(1,72 \%$ ao mês) em vários períodos, mostrando que os portfólios gerados são eficientes. Considerando as duas formas de calcular o beta, as carteiras geradas 
comportam-se de maneira muito semelhante no período considerado, sendo que no período final, a métrica do B30 apresentou uma pequena vantagem.

O comportamento de ambas as carteiras é muito semelhante ao do índice Ibovespa, como era de se esperar. No entanto, de agosto a outubro de 2007, o índice apresenta uma ascenção que as carteiras não conseguem atingir, sugerindo que o beta inicialmente considerado para os ativos não representa bem seu comportamento relativo ao mercado nesse intervalo, indicando que novas escolhas de portfólios ótimos deveriam ser efetivadas sempre que o beta variar.

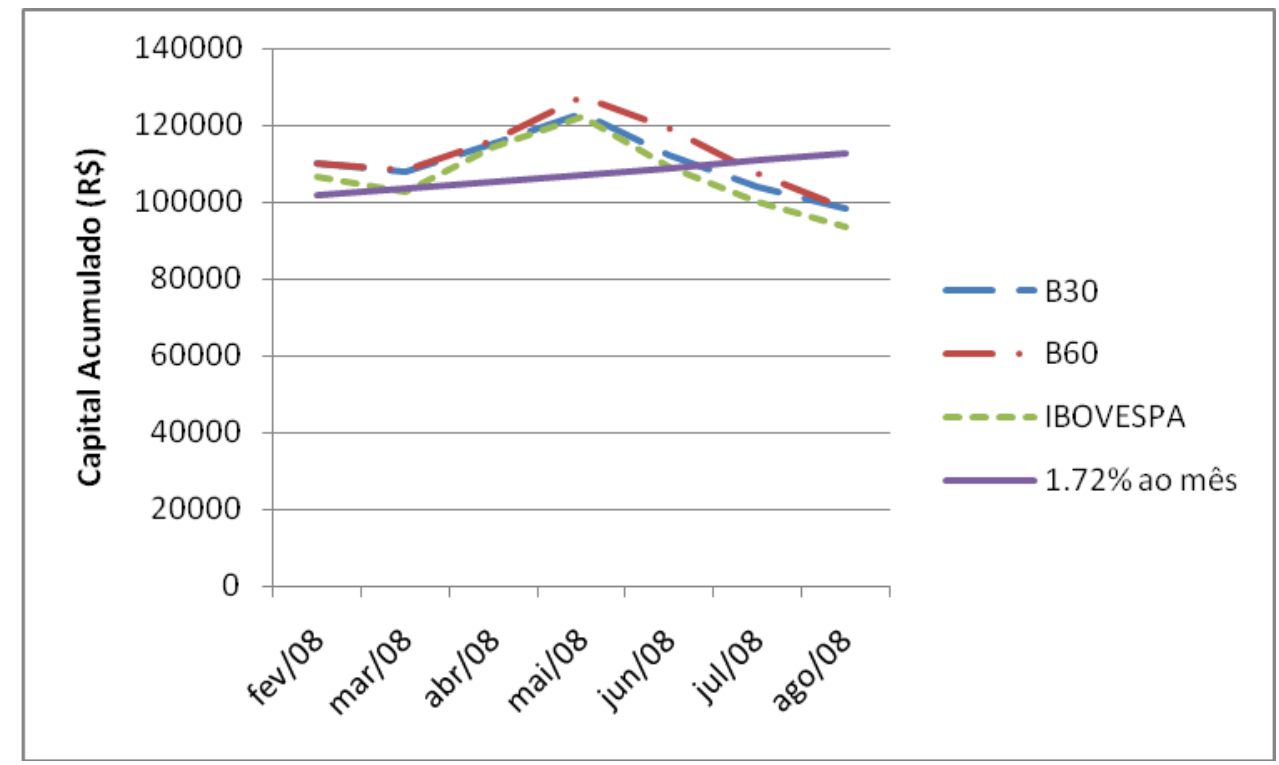

Figura 5.10 - Desempenho das carteiras geradas em jan/2008 utilizando o beta.

A Figura 5.10 ilustra o desempenho das carteiras geradas em janeiro de 2008 que apresentam o maior valor da medida de segurança. Novamente as carteiras possuem comportamento muito próximo entre si e em relação ao Ibovespa. Nos períodos analisados, menos numerosos que na analise anterior, a carteira obtida com os betas calculados em 60 meses mostrou-se superior às demais, possuindo retorno mensal superior a 1,72\% em grande 
parte dos períodos, e sempre estando acima do Ibovespa. Os betas não parecem se distorcer no período considerado, não havendo grandes variações em nenhum período.

\section{5 - Conclusões}

A análise do beta das carteiras em problemas de portfólios ótimos mostra um grande potencial em períodos de baixa no mercado, indicando que a metodologia pode ser aplicada ao problema de escolha ótima de portfólio multi-período. Em períodos de estabilidade ou ascensão, as carteiras obtidas mostram-se muitas vezes inferiores àquelas obtidas sem a consideração do beta. Seriam necessários mais dados para averiguar seu desempenho em longo prazo, mas há indícios de que o valor de beta inicialmente considerado passe a ser corrompido com o passar do tempo, pois com a análise em longo prazo feita percebe-se queda no desempenho das carteiras após um horizonte de tempo.

Outra abordagem que pode ser estudada é a possibilidade de usar os valores de beta dos ativos no cálculo do retorno esperado das mesmas, que podem ser, então, obtidos pela fórmula do CAPM (Capital Asset Pricing Model): $r_{j}=r_{f}+\beta_{j}\left(r_{M}-r_{f}\right)$

Dessa forma, o retorno esperado do ativo, $r_{j}$, passaria a ser calculado em termos de $r_{f}$, que representa o retorno de um investimento livre de risco, como por exemplo a taxa SELIC, seu beta e o prêmio pelo risco, calculado como $\left(r_{f}-r_{M}\right)$, onde $r_{M}$ é o retorno do mercado, medido por algum índice, como o Ibovespa. Essa mesma abordagem é adotada em Rainer Bauler (2008), e representa uma alternativa ao cálculo de retorno esperado como média aritmética dos retornos passados, que se mostrou uma estimativa muito otimista, estando muito acima do retorno observado na grande maioria dos experimentos realizados. 


\section{Capítulo 6 - Conclusões e Trabalhos Futuros}

Neste trabalho foi estudado o problema de escolha de portfólio ótimo sob a perspectiva apresentada inicialmente por Harry Max Markowitz em 1952, que leva em consideração os retornos passados de ativos para então escolher um portfólio eficiente do ponto de vista de seu nível de risco e de retorno esperados. Foram estudadas modelagens com medidas de risco alternativas à variância utilizada no modelo $M-V$, que tornaria o problema não-linear.

O modelo e o método de solução propostos em Mansini e Speranza (2005) foram abordados em detalhes. As autoras utilizam o semi-desvio absoluto da média como medida de risco e incorporam características reais ao problema, tais como: adição de custos fixos de investimento e compra de ações por lotes. O método de resolução proposto mostrou-se eficiente, visto que todos os exemplos considerados no trabalho foram resolvidos rapidamente. No entanto, a análise dos resultados mostrou que o retorno esperado dos portfólios ótimos obtidos representa uma medida muito otimista de seu real desempenho. Buscando melhorar os resultados obtidos, foram avaliadas duas hipóteses.

A primeira baseia-se na ponderação dos cenários dos quais são extraídos os retornos históricos das ações, tornando mais prováveis os cenários cujas observações são menos dispersas, em contraste aos cenários equiprováveis, que são largamente utilizados. Os experimentos foram realizados de forma a avaliar o desempenho de conjuntos distintos de ações na modelagem e na solução do problema, com o objetivo de estudar as vantagens de cada um deles. O mercado brasileiro foi escolhido para análise, visto que é um mercado pouco abordado do ponto de vista de escolha ótima de portfólio. Esse estudo revelou que existem 
vantagens em se utilizar o método de ponderação para os cenários, visto que os retornos efetivos das carteiras escolhidas foram substancialmente maiores em média e mediana para a maioria dos experimentos escolhidos. Além desses resultados, observou-se que a consideração de um grupo de ações mais seleto para o problema, o grupo de ativos pertencentes ao $I G C$, também representa melhoras na solução, indicando que existem fatores não considerados explicitamente no problema que podem melhorar seus resultados. No entanto, as carteiras apresentaram, de modo geral, um alto nível de risco não-diversificável em longo prazo, e o retorno esperado ainda mostrou-se uma medida muito otimista do real desempenho da carteira.

A segunda hipótese explorada neste trabalho foi o número de ativos que compõem a carteira e o comportamento da mesma em relação ao comportamento do mercado. O objetivo é restringir o comportamento da carteira em relação ao mercado, utilizando para tal, o valor do beta da carteira. Além disso, visando reduzir o risco diversificável, também foi proposto um limite mínimo para o número de ações que compõem a carteira. Também foi desenvolvido um método para a obtenção de curvas de Pareto para o problema, onde os objetivos de risco e de retorno são confrontados em um mesmo gráfico, para que o investidor tome a decisão da carteira que melhor representa seus interesses.

Os resultados obtidos mostraram que o controle do beta da carteira pode ser vantajoso em curto prazo, onde, mesmo em períodos de queda brusca no mercado, foi possível obter elevados níveis de retornos. Todavia, os benefícios tendem a se deteriorar em longo prazo, indicando que a carteira deve ser recalculada periodicamente, como também se observou para os casos onde o beta não foi considerado. Também se pode notar que, em todas as instâncias consideradas, os portfólios que apresentaram os menores níveis de risco possuíam, 
tipicamente, comportamentos muito ruins, obtendo resultados negativos no período da criação da carteira, indicando que quando se prioriza o risco, outras medidas devem ser consideradas.

Para a solução dos desafios encontrados, o problema de escolha de portfólio ótimo pode ser estudado futuramente sobre diferentes óticas. Existem trabalhos que abordam o problema de escolha de portfólio ótimo multi-período, visando maior controle do comportamento em longo prazo do investimento, e que utilizam otimização robusta, de forma a tratar os retornos dos ativos como dados incertos, e representar o risco como o erro total nas previsões de retorno dos ativos, como em Bertsimas e Pachamanova (2006).

Outras mudanças mais simples também poderiam ser propostas para o modelo. Uma delas é calcular o retorno esperado dos ativos através do CAPM, como em Baule (2008), utilizando um valor do retorno do mercado previsto através de séries temporais. Assim como em Guastaroba et al. (2007), podem ser consideradas outras formas além do levantamento dos retornos históricos na consideração dos cenários para o problema. Enfim, medidas alternativas de risco, como em Mansini, Ogryczak e Speranza (2007) (CVaR: Conditional Value at Risk) podem ser consideradas também para o caso inteiro-misto do problema.

As propostas apresentadas neste trabalho também poderiam ser utilizadas em mercados internacionais, de forma a medir quão relacionados os ganhos de desempenho estão às características específicas do mercado brasileiro. Sabe-se que em mercados eficientes, toda a informação referente a um ativo já está contabilizada em seu preço. Uma vez que o mercado brasileiro apresenta menor número de traços de mercado eficiente em relação à maioria dos mercados estudados na literatura, não se pode concluir que os ganhos de desempenho se repetem para qualquer que seja o mercado escolhido. 
Apesar das extensas possibilidades de exploração do problema, os resultados obtidos contribuem fortemente para novos estudos na área de pré-seleção dos dados dos ativos antes destes serem incorporados ao problema, principalmente para o mercado brasileiro, que carece de tantos estudos na área. Mostrou-se também que as soluções encontradas para o problema de escolha ótima de portfólios são aplicáveis na prática, e possuem em geral bons resultados. 


\section{Referências Bibliográficas}

Albuquerque, G. U. V., Toledo, F. M. B. e Kalatzis, A. E. G. (2008), "Um estudo sobre a influência da ponderação de cenários para portfólios ótimos", XIV Latin Ibero American Congress on Operations Research (CLAIO 2008) - Book of Extended Abstracts.

Baule, R. (2008), "Optimal portfolio selection for the small investor considering risk and transaction costs", Springerlink.com.

Bertsimas D., e Pachamanova D. (2006), "Robust multiperiod portfólio management in the presence of transaction costs", Computers and Operations Research, Ed Elsevier.

Chang-Chun Lin, e Yi-Ting Liu (2006), “Genetic algorithms for portfolio selection problems with minimum transaction lots", European Journal of Operational Research 185, 393-404.

Ching-Ter Chang (2005), "A modified goal programming approach for the mean-absolute deviation portfolio optimization model", Applied Mathematicss and Computation 171, 567572.

Doerner, K. F., Gutjahr, W. J. et al. (2004), "Pareto ant colony optimization: a metaheuristic approach to multiobjective portfolio selection”, Annals of Operations Research 131, 79-99.

Doerner, K. F., Gutjahr, W. J., Hartl, R. F., Strauss, C. e Stummer, C. (2006), "Pareto ant colony optimization with ILP preprocessing in multiobjective project portfolio selection", European Journal of Operational Research 171, 830-841.

Elton, E. J. et al. (2004), “Moderna Teoria de Carteiras e Análise de investimentos”, Ed Atlas.

Feinstein C. D. e Thappa, M. N. (1993), "Notes: a reformulation of a mean-absolute deviation portfolio optimization model", Management Science 39, 1552-1553. 
Gitman, L. J. (2004), “Princípios de Administração Financeira”, 10e., Ed Afiliada.

Guastaroba, G., Mansini, R. E Speranza M. G. (2007), "On the effectiveness of scenario generation techniques in single-period portfolio optimization", European Journal of Operational Research 192 (2009), 500-511

Kellerer, H., Mansini, R. e Speranza, M.G. (2000), "Selecting portfolios with fixed costs and minimum transaction lots", Annals of Operations Research 99, 287-304.

Konno, H. e Koshizuka T. (2005), "Mean-absolute deviation model”, IIE Transactions 37, 893900.

Konno, H. e Yamazaki, H (1991), "Mean-absolute deviation portfolio optimization model and its applications to Tokyo stock market”, Management Science 37, 5 p. 519.

Konno, H. e Wijayanayake, A. (2001), "Portfolio optimization problem under concave transaction costs and minimal transaction unit constraints", Mathematical Programming 89, 2 p. 233-250.

Mansini, R., Ogryczak, W. e Speranza, M. G. (2003), "LP solvable models for portfolio optimization: a classification and computational comparison”, IMA Journal of Management Mathematics 14, p.187-220.

Mansini, R., Ogryczak, W. e Speranza, M. (2007), “Conditional value at risk and related linear programming models for portfolio optimization", Annals of Operational Research 152, p. 227-256.

Mansini, R. e Speranza, M. G. (1999), "Heuristic algorithms for the portfolio selection problem with minimum transaction lots", European Journal of Operational Research 114, p. 219-233. 
Mansini, R. e Speranza, M. G. (2005), “An exact approach for portfolio selection with transaction costs and rounds", IIE Transaction 37, p. 919-929.

Markowitz H. (1952), "Portfolio selection”, Journal of Finance 7, p. 77-91.

Papahristodoulou, C. e Dotzauer, E. (2004), "Optimal portfolios using linear programming models", Journal of the Operational Research Society 55, p. 1169-1177.

Patel, N.R. e Subrahmanyam, M. G. (1982), “A simple algorithm for optimal portfolio selection with fixed transation costs", Management Science 3, 28 p. 303-314.

Reddy, M. J. e Kumar, D. N. (2007), "Multi-objective particle swarm optimization for generating optimal trade-offs in reservoir operation”, Hydrol. Process. 21, 2897-2909.

Sharpe, W. F. (1971), "A linear programming approximation for the general portfolio analysis problem”, The Journal of Financial and Quantitative Analysis 6, 5 p. 1236-1275.

Speranza, M.G. (1996), “A heuristic algorithm for a portfolio optimization model applied to the Milan stock market”, Computers and Operations Research 23, 5 p. 433-441.

Stone, B. K. (1973), “A linear programming formulation of the general portfolio selection problem", The Journal of Financial and Quantitative Analysis 8, 4 p. 621-636.

Whitmore, G.A. e Findlay, M.C. (eds.) (1978) Stochastic Dominance: An approach to decisionmaking under risk, D.C. Heath, Lexington, M.A. apud in Mansini, R. e Speranza, M. G. (2005).

Young, M. R. (1998), “A minimax portfolio selection rule with linear programming solution”, Management Science 44, p. 673-683. 


\section{APÊNDICE A - Ponderação de cenários em problemas lineares}

O desempenho do método de ponderação apresentado no Capítulo 4 deste trabalho foi estudado previamente em três modelos lineares distintos. Esses resultados preliminares foram compilados em um trabalho, submetido e apresentado no XIV Congreso Latino HiberoAmericano de Investigación de Operaciones, que ocorreu de 09/09/2008 a 12/09/2008, em Cartagena de Indias, Colômbia. Esta seção se destina à apresentação deste trabalho. 


\title{
UM ESTUDO SOBRE A INFLUÊNCIA DA PONDERAÇÃO DE CENÁRIOS PARA PORTFÓLIOS ÓTIMOS
}

\author{
Guilherme U. V. Albuquerque*, Aquiles E. G. Kalatzis ${ }^{\dagger}$ e Franklina M. B. \\ Toledo $^{\dagger \dagger}$ \\ Universidade de São Paulo \\ São Carlos, Brasil \\ e-mail: *ulliana@icmc.usp.br, ${ }^{\dagger}$ aquiles@sc.usp.br, ${ }^{\dagger \dagger}$ fran@icmc.usp.br.
}

\section{INTRODUÇÃO}

$\mathrm{Na}$ área financeira, um dos maiores problemas relacionados ao investimento em ações refere-se à composição ótima de uma carteira (ou portfólio) de ações. O objetivo é escolher a carteira que melhor satisfaça às exigências do investidor, que estão relacionadas ao risco e ao retorno que o portfólio ou a ação oferecem, tendo como base as realizações passadas das ações candidatas a comporem a carteira.

O problema de escolha de portfólio ótimo foi inicialmente modelado por Harry Max Markowitz em 1952 [1], o qual ficou conhecido como modelo da média-variância (M-V). O modelo possui grande importância teórica, mas devido às suas desvantagens computacionais, por ser um modelo quadrático, seu uso torna-se mais restrito. Alguns autores utilizam heurísticas para obter um valor aproximado para a solução do problema [2]. Outros, propõem modelos lineares baseados em medidas de risco alternativas à variância, como o desvio absoluto da média [3] ou o semi-desvio absoluto da média [4], ou então não tratam diretamente do risco, como o problema de maximização do mínimo retorno esperado (maximin) [5].

Quando os problemas são formulados segundo os modelos acima, os autores tipicamente assumem que os cenários passados, que contêm as realizações das ações em dado horizonte de tempo, são equiprováveis. O objetivo deste trabalho é estimar a probabilidade dos cenários considerados utilizando as oscilações históricas do mercado como base, e avaliar até que ponto a nova informação acerca dos cenários implica na elaboração de portfólios sujeitos a menores riscos.

\section{MÉTODO DE PONDERAÇÃO DE CENÁRIOS}

As modelagens do problema de escolha de portfólio ótimo assumem que um investidor pode alocar seu capital em $n$ ações distintas, com taxas aleatórias de retorno. Seja $R=\left(R_{1}, R_{2}, \ldots, R_{n}\right)$ o vetor das $n$ variáveis aleatórias que descrevem o retorno das $n$ ações distintas. As realizações de $R_{j}$, representadas por $r_{j t}$ para cada período (ou cenário) $t$ considerado, são obtidas através do levantamento de dados históricos conhecidos. Tipicamente, são considerados cenários mensais. Considerando um total de $T$ cenários, a probabilidade $p_{t}=P\left\{\left(R_{1}, R_{2}, \ldots, R_{n}\right)=\left(r_{1 t}, r_{2 t}, \ldots, r_{n t}\right)\right\}$ para $t=1,2, \ldots, T$ representa a probabilidade de ocorrência do cenário $t$.

Como o problema deve lidar com incertezas nos dados de entrada, o portfólio ótimo não fornece um resultado (em termos de retorno) garantido. Seu retorno esperado é obtido em termos dos retornos esperados das ações, $\bar{r}_{j}=\sum_{t=1}^{T} p_{j} r_{j t}$ para cada ação $j, j=1,2, \ldots, n$. No entanto, não é possível conhecer os valores de probabilidade exatamente. Tipicamente, considera-se que os cenários sejam equiprováveis, prática que não implica em falhas teóricas no modelo, que passa a expressar os retornos esperados em termos dos retornos médios. Essa simplificação, embora não amplamente discutida na literatura, pode estar relacionada à eficiência do mercado abordado pelos trabalhos, tipicamente mais eficientes que os mercados latino-americanos como o brasileiro. 
Com o objetivo de analisar até que ponto a consideração do comportamento do mercado é relevante para a modelagem dos problemas, este trabalho propõe um método para atribuir valores distintos à $p_{t}, t=1,2, \ldots, T$. O método se utiliza dos retornos mensais do mercado, observados durante um período de tempo (anual) suficientemente grande, para descrever a variação dos retornos em dado mês do ano. A ponderação dos cenários referentes à dado mês é efetuada tendo como base a variação dos retornos do mercado naquele mês. Deseja-se atribuir valores de probabilidades menores aos cenários cuja variação é grande, e maiores quando a variação é pequena. Com isso, os cenários considerados mais estáveis (com menor variação) tornam-se mais prováveis em relação aos demais no modelo.

A variação é mensurada pelo desvio padrão dos retornos periódicos do mercado, referente a cada período do ano. Sendo assim, os valores de probabilidade em cada período $t$ devem ser inversamente proporcionais ao desvio padrão do período correspondente. Por simplificação, a fórmula abaixo pressupõe uma equivalência entre o número de períodos do ano considerados (neste caso, os meses) e os cenários a serem considerados no modelo.

$$
p_{t}=\frac{K}{\sigma_{t}}
$$

Como a soma de todas as probabilidades deve ser igual a $1, K$ pode ser facilmente obtido pela expressão abaixo.

$$
K=\frac{1}{\sum_{t=1}^{T}\left(1 / \sigma_{t}\right)}
$$

Conhecido o valor de $K$, obtido em (2), basta substituir seu valor em (1) para todo $p_{t}$. Para estimar a probabilidade dos cenários nos casos em que o número de cenários é superior ao número de períodos anuais considerados, basta definir uma correspondência entre os valores de $p_{t}, t=$ $1,2, \ldots, T$ e os desvios $\sigma_{p}$, já estimados para os períodos $p=1,2, \ldots, P$.

\section{RESULTADOS PARCIAIS}

Testes preliminares foram realizados utilizando-se três modelos propostos na literatura: o modelo de minimização do desvio absoluto da média (MDAM) [3], o modelo maximin [5] e uma relaxação linear do modelo de maximização da medida de segurança (MMS) proposta em [4]. Para a coleta de dados, foram utilizados os retornos mensais dos ativos dos índices IGC e Ibovespa, do mercado brasileiro, nos períodos de 2004 e 2005 . O objetivo dos testes era gerar carteiras ótimas para todos os períodos (meses) de 2005 utilizando os dados de 2004 e o critério de ponderação de cenários, e comparar o desempenho (em termos de retorno) esperado e efetivo das carteiras durante o período. A medida de dispersão utilizada foi a média da diferença (em módulo) dos retornos esperados e efetivos das carteiras no ano. Para a ponderação de cenários, foram utilizados os desvios mensais dos retornos do índice ibovespa em três horizontes distintos: considerando os desvios desde 1986, desde 1994 (que marcou o início do plano real) e desde 2000 (apenas o passado recente). Foram utilizados os softwares da iniciativa COIN-OR na solução dos problemas. Os resultados encontram-se na Tabela 1. 
Os testes mostram que os portfólios ótimos em cada período possuem um erro anual médio menor quando há distinção entre os cenários. Isso significa que, em média, o retorno esperado do portfólio ótimo em cada período era mais próximo ao retorno efetivo nos casos onde a ponderação foi utilizada, indicando que há um menor risco associado às carteiras nesse caso. Todavia, o fato de cada horizonte para o cálculo do desvio padrão fornecer resultados melhores em um dos modelos requer mais estudo.

\section{CONCLUSÕES E TRABALHOS FUTUROS}

A consideração de probabilidades distintas para os cenários abordados no problema de portfólio ótimo parece influenciar fortemente na escolha das soluções e portanto, mensurando as probabilidades eficientemente, há a possibilidade de se obter resultados sujeitos à menor risco.

Além da aplicação da metodologia descrita neste trabalho na geração das carteiras utilizando os dados atualizados do mercado brasileiro (2006, 2007 e 2008), pretende-se fazer um paralelo da análise de ponderação de cenários com eficiência de mercado, avaliando mercados mais eficientes e menos eficientes que o mercado brasileiro, e verificar se há menor ou maior influência das oscilações do mercado nos resultados. Também considera-se utilizar a mesma metodologia em outros modelos, mais robustos e adaptados à cada mercado específico. Há ainda a possibilidade de adaptar o método de ponderação, na busca de uma metodologia mais robusta.

\section{REFERÊNCIAS}

[1] Markowitz H. (1952), "Portfolio selection", Journal of Finance 7, p. 77-91.

[2] Chang-Chun Lin, e Yi-Ting Liu (2007), "Genetic algorithms for portfolio selection problems with minimum transaction lots", European Journal of Operational Research 185 (2008) 393404.

[3] Konno, H. e Yamazaki, H (1991), "Mean-absolute deviation portfolio optimization model and its applications to Tokyo stock market", Management Science 37, 5 p. 519.

[4] Mansini, R. e Speranza, M. G. (2005), "An exact approach for portfolio selection with transaction costs and rounds", IIE Transaction 37, p. 919-929.

[5] Young, M. R. (1998), "A minimax portfolio selection rule with linear programming solution", Management Science 44, p. 673-683. 
Tabela 1. Erro Médio obtido para as carteiras mensais geradas no ano de 2005

\begin{tabular}{|r|r|r|r|}
\hline Cenários & MDAM & Maximin & MMS \\
\hline Equiprováveis & 6019,0608 & 6879,5122 & 8207,7808 \\
\hline Ponderação - 1986 a 2004 & $\mathbf{5 7 5 4 , 8 4 0 5}$ & 6932,2188 & 8736,7717 \\
\hline Ponderação - 1995 a 2004 & 5783,4131 & $\mathbf{6 8 4 5 , 8 2 3 0}$ & 9389,8358 \\
\hline Ponderação - 2000 a 2004 & 6205,1048 & 7001,7022 & $\mathbf{6 7 0 8 , 4 6 8 3}$ \\
\hline
\end{tabular}

